\title{
NUEVOS PLANTEAMIENTOS EN LA DOCENCIA UNIVERSITARIA EN TURISMO: PROPUESTA DIDÁCTICA PARA EL ESTUDIO DE LOS RECURSOS TERRITORIALES TURÍSTICOS
}

\author{
Rafael Garzón-García* \\ Universidad de Córdoba \\ https://orcid.org/0000-0002-2887-5277 \\ Gema Florido-Trujillo* \\ Universidad de Córdoba \\ https://orcid.org/0000-0001-9961-1036
}

\section{RESUMEN}

Se plantea un proyecto didáctico para la asignatura de Recursos Territoriales Turísticos, considerada como clave en el estudio universitario de la dimensión geográfica del fenómeno turístico. El trabajo toma en consideración la realidad existente a este respecto en el sistema universitario español, caracterizada por una evidente heterogeneidad. Se ofrece una propuesta en pro de la deseable clarificación, a partir de lo cual se detalla el desarrollo conceptual y metodológico de la asignatura, desde una perspectiva eminentemente pragmática y aplicada, en aras de la mejora docente.

Palabras clave: Docencia universitaria, Recursos territoriales turísticos, Turismo y territorio

New approaches to University teaching in Tourism: Didactic proposal for the study of Tourist Territorial Resources

\section{ABSTRACT}

A didactic plan is proposed for Territorial Tourism Resources, considered as a key subject for the university study of the geographical dimension of tourism. The study takes

Fecha de recepción: 24 de noviembre de 2019

Fecha de aceptación: 26 de mayo de 2020

* Departamento de Ciencias Sociales, Filosofía, Geografía y Traducción e Interpretación. Grupo de Investigación "Estudios de Geografía". Universidad de Córdoba. Plaza Cardenal Salazar, 3. 14003 CÓRDOBA (España).E-mail: rafael.garzon@uco.es; gema.florido@uco.es 
into account the reality in this regard in the Spanish university system, characterized by an obvious heterogeneity. A proposal for the desirable clarification is offered, from which the conceptual and methodological development of the subject is detailed, from an eminently pragmatic and applied perspective, for the sake of teaching improvement.

Keywords: University teaching; Tourism territorial resources; Tourism and territory.

\section{INTRODUCCIÓN}

El trabajo que se presenta, resultado directo de la praxis de la enseñanza universitaria, asume un doble carácter: por una parte, reflexivo, y, por otra, eminentemente pragmático y didáctico.

Debe destacarse que, pese a que durante los últimos años han aparecido diversas aportaciones que han abordado la dimensión formativa y profesional de los estudios de Turismo (Majó, Galí y Ministral, 2000; Majó, 2005; García y Pérez, 2008; Torres y otros, 2017; Dorta-Afonso, 2018, entre otras), lo cierto es que han sido muy escasas las orientadas específicamente a la mejora educativa.

En esta línea, este artículo trata de ofrecer un proyecto docente claro y bien fundamentado respecto de una asignatura clave en el currículum universitario de Turismo: Recursos Territoriales Turísticos. El trabajo parte de una reflexión previa sobre los contenidos territoriales en el Grado, uno de los bloques temáticos fundamentales del mismo según lo establecido en el Libro Blanco (ANECA, 2004); y, sobre ello, se profundiza en segunda instancia en el desarrollo específico de la materia.

Respecto de esto último, aunque obviamente resulta inviable un análisis exhaustivo, se le ha dado el suficiente nivel de concreción como para que pueda ser de utilidad para profesorado, alumnado e, incluso, para la posible revisión de los planes de estudio, en un contexto de notable disparidad entre las universidades españolas. La proposición tiene un acusado afán didáctico e innovador, resultando sistemática y visual. Se incide muy especialmente en los principales conceptos y contenidos, remarcando la interrelación entre ellos que define el hilo argumental de la asignatura. E igualmente, se pone especial énfasis en la dimensión metodológica, aportando materiales de distinto carácter, así como ejemplos de caso empleados en la enseñanza.

El resultado es una propuesta abierta, que pretende guiar a la reflexión, pero que no renuncia, al mismo tiempo, a ser una herramienta útil para la que estimamos como necesaria mejora docente en el campo del estudio territorial del fenómeno turístico.

2. LA INSERCIÓN DE LA ASIGNATURA RECURSOS TERRITORIALES TURÍSTICOS EN EL MARCO DE LOS ESTUDIOS UNIVERSITARIOS DE TURISMO

\subsection{La ineludible dimensión geográfica o territorial del fenómeno turístico}

La pluralidad de aspectos y componentes que confluyen en torno a una actividad tan compleja como la turística es un hecho indiscutible que se refleja en la transversalidad 
temática de las obras que tratan de acercarse a su comprensión y que se hace patente en el propio diseño del Grado de Turismo en el sistema universitario español.

En el contexto de dicha transversalidad, no puede obviarse la relevancia de la Geografía en el entendimiento y aproximación científica al fenómeno turístico, una importancia, sin embargo, no suficientemente reconocida hasta tiempos relativamente recientes (Vera. Coord., 2014). Dicha carencia se ha manifestado en un doble sentido: tanto desde la disciplina, que tradicionalmente ha prestado escasa atención al turismo, como desde la investigación más específica, que en no pocos casos ha soslayado el territorio como variable imprescindible para la comprensión de la actividad. Muestra inequívoca de ello es, por ejemplo, que la célebre Teoría del ciclo de vida del destino turístico (Butler, 1980) representase un modelo explicativo sobre su evolución, de sesgo cuantitativo y economicista, definido por una falta de consideración de la base geográfica de los espacios turísticos y sus diferentes tipologías, lo cual limita en gran medida la validez de sus postulados teóricos y de su posible aplicabilidad práctica (Vera, Coord., 1997).

En todo caso, la creciente vinculación que ya desde las últimas décadas se viene manifestando entre el Turismo y la Geografía explica que un campo temático específico de estos estudios universitarios sea el relativo a la vertiente territorial del mismo.

En efecto, como reiteradamente muestra la bibliografía especializada (Barrado, 2004; Vera, Coord., 1997; 2013; Antón y otros, 2007; Lois, 2008; Barrado y Ávila, 2010; Vera y Baños, 2016), el turismo constituye un hecho social con trascendentales consecuencias en múltiples ámbitos (económico, cultural, político, tecnológico, etc.),pero, ante todo, se conforma como una práctica eminentemente territorial en la que el componente geográfico adquiere un particular protagonismo. Sobre la base de las estrechas e indisolubles interrelaciones que se establecen entre ambas esferas, cabe hablar pues de la ineludible dimensión territorial del fenómeno turístico. Las razones que apoyan esta afirmación son palmarias.

De entrada, la actividad turística implica un desplazamiento, lo que ya es motivo suficiente para considerarla como "una de las acciones humanas más genuinamente territorial" (Vera, Coord., 2014, 79-80). Así, la necesidad de salvar la distancia entre el origen y el destino de los visitantes impone una movilidad que vendrá condicionada por variables de clara naturaleza geográfica como su localización y accesibilidad, estableciéndose en función de ellas, y a pesar de las sustanciales mejoras experimentadas por los medios de transporte, significativas diferencias entre las distintas áreas del mundo receptoras de viajeros en sus posibilidades de inclusión en los mercados turísticos (Vera y Baños, 2016).

Por otra parte, la práctica se ha de desarrollar necesariamente sobre un espacio determinado, concretándose formalmente sobre él. Podemos decir que el territorio es el escenario que acoge las experiencias turísticas, que, a diferencia de otras actividades de carácter no espacial, necesitan indefectiblemente un marco que les sirva de soporte. No obstante, más allá de esa función de mero contenedor, dicho espacio presenta una serie de rasgos físicos y humanos que, a escala local, lo particularizan y que son los que, en último término, los usuarios identifican y aprecian hasta el punto de impulsarlos a acercarse hasta él. Se trata de los recursos que motivan el desplazamiento del turista, habitualmente configurados como bienes del patrimonio natural, cultural y paisajístico, siendo el carácter de estos el que condicionará de manera más decisiva el potencial y el atractivo del destino y el que lo dotará de su sesgo e imagen específica (López, 1998; Ávila y Barrado, 2005). Y, junto 
a ellos, aparecen otros factores ambientales (clima, vegetación, relieve, hidrología, además del proceso de humanización) que, cuando no llegan a erigirse en atractivos turísticos, sí conforman el marco geográfico y tienen una influencia directa sobre el desarrollo de la actividad, resultando decisivos en determinados ámbitos (considérense las limitaciones que conlleva la falta de agua, un relieve muy abrupto o un régimen de lluvias torrencial, entre otros muchos posibles ejemplos). Por todo ello, no es casual que la identidad y singularidad geográficas y la calidad ambiental se constituyan en importantes argumentos de promoción y que la preocupación por la sostenibilidad esté creciendo de manera significativa entre todos los estamentos vinculados al sector, cada vez más conscientes de que una visita satisfactoria pasa, obligatoriamente, por la adecuada preservación del lugar de acogida (Barrado y Ávila, 2010; Simancas, Coord., 2016).

Un espacio que, por otra parte, suele verse afectado por la propia funcionalidad turística desde el momento en que precisa incorporar nuevos componentes y adaptar sus estructuras (en mayor medida cuanto más desarrollada esté la actividad) para dar respuesta a las necesidades de los usuarios. Tales elementos (infraestructuras, equipamientos o servicios) conforman productos, tanto turísticos como no específicamente turísticos, que posibilitan la satisfacción del visitante (Díaz, 2011).En este sentido, debe remarcarse que una de las peculiaridades del turismo frente a otras actividades de proyección económica estriba en que la producción y el consumo se efectúan en el mismo ámbito; dicho de otro modo, los productos son consumidos in situ, ya que es el usuario, el turista, el que se traslada allí donde se genera o produce la oferta gracias a la atracción suscitada por recursos inevitablemente vinculados a un entorno determinado, el territorio turístico.

Qué duda cabe que la confluencia de la producción y el consumo turísticos sobre un mismo espacio genera indudables impactos sobre él, pudiendo llegar incluso a transformarlo de forma sustancial. La ocupación del suelo, los cambios en los ecosistemas y los paisajes, el importante consumo de agua y energía, pero también la modificación de las estructuras y relaciones socioeconómicas y la adopción de nuevos patrones culturales son sólo algunos de los efectos directos que el turismo tiene sobre los lugares de acogida (Vera, Coord., 1997; 2014; Barrado, 2004; Vera y Baños, 2016).

La interacción, no obstante, es de doble dirección. También la creación de productos turísticos va a verse muy mediatizada por los rasgos del territorio y por las decisiones que se adopten sobre él. En este sentido, ya se indicó que los factores ambientales (naturales y antrópicos) condicionan el desenvolvimiento y la formalización de la actividad; pero también lo hacen directamente las intervenciones derivadas del uso económico y social del espacio. Así, un proceso de humanización armónico conlleva la aparición de un legado cultural que, ya sea configurado específicamente como recurso turístico ya sea como factor complementario, puede ser positivamente valorado por la demanda. Por el contrario, intervenciones agresivas con el medio suponen una degradación capaz de provocar rechazo entre los posibles visitantes; como también lo hace la presencia de actividades perjudiciales o incompatibles con el turismo, ya que estas pueden afectar negativamente a la calidad de la experiencia vivida. Siendo así, parece evidente que las decisiones de intervención sobre el territorio, muchas de ellas tomadas desde el ámbito de la ordenación y la planificación, repercutirán de forma directa sobre el modelo turístico y su funcionamiento (Barrado y Ávila, 2010; Vera, Coord., 2014; Simancas, Coord., 2016). 
El análisis de la dimensión geográfica constituye, pues, un área de entidad dentro de la aproximación globalizadora y trasversal al fenómeno turístico, que podríamos conceptualizar como los estudios geográfico-turísticos o territoriales-turísticos. En el epígrafe que sigue se analiza cómo se ha concebido y diseñado este campo de conocimiento en la universidad española, a modo de contextualización imprescindible para la propuesta metodológica que, en relación con la asignatura de Recursos Territoriales Turísticos, se ofrecerá posteriormente.

\subsection{El estudio de la vertiente territorial del turismo: revisión crítica a partir del panorama español}

Hemos visto que la dimensión territorial del turismo resulta compleja y prolija en sí misma, constituyendo un vector clave para la comprensión global del sistema turístico. Revisamos por ello en este epígrafe cómo se ha organizado la docencia de esta vertiente en el panorama universitario español, cuestión respecto a la cual resulta necesario aclarar que, partiendo del Libro Blanco del Título de Grado en Turismo elaborado por la Agencia Nacional de Evaluación de la Calidad y Acreditación (ANECA, 2004), asumirá una ulterior concreción normativa en los planes de estudio de aquellas universidades que han incorporado dicho Grado a su oferta académica.

El Libro Blanco se perfila como una propuesta no vinculante, pero de extraordinario valor orientativo para el diseño del título en el contexto del Espacio Europeo de Educación Superior (EEES) en función de su carácter de documento de reflexión, síntesis y consenso interuniversitario, siendo lo suficientemente flexible como para poder adaptarse a las demandas de un sector en constante evolución (ANECA, 2004).

Dicha propuesta se asienta en las competencias (transversales y específicas) que debe poseer un graduado en Turismo, con contenidos agrupados en Bloques de Materias por Competencias (BMC), que definen la estructura básica del Grado (García y Pérez, 2008). Partiendo de los que se estimaban como componentes esenciales del sistema turístico, el Libro Blanco estableció ocho $\mathrm{BMC}^{1}$, desde una visión amplia y trasversal (en consonancia con la multidisciplinariedad propia de la praxis turística). Tres de estos Bloques, Fundamentos y dimensiones del turismo, Recursos y productos turísticos y Destinos turísticos, podían enmarcarse dentro del gran campo temático de los estudios territoriales turísticos.

En cada BMC estaría representada más de un área de conocimiento (en aras de la ya referida multidisciplinariedad y de una flexibilidad que permitiera atender a la situación de cada universidad). Se dispusieron para ello desde el Libro Blanco los denominados Ámbitos de Conocimiento (AmC), distintas aproximaciones disciplinares al turismo, vinculándose a cada uno de ellos áreas afines. De los diez AmC propuestos, dos se situaban claramente en el marco de la dimensión territorial de la actividad: el AmC-1 (Turismo desde la perspectiva del territorio) y el AmC-8 (Planificación y gestión pública del turismo). Todos ellos habrían de desarrollar las competencias asignadas en los BMC.

1 A saber: Dirección y gestión de empresas de servicios turísticos, Fundamentos y dimensiones del turismo, Gestión de alojamientos y restauración, Distribución turística y transportes, Recursos y productos turísticos, Destinos turísticos, Lenguas extranjeras aplicadas al turismo, y Practicum (ANECA, 2004). 
En este contexto, el Libro Blanco estipulaba el papel de los AmC en los diferentes $\mathrm{BMC}$, estableciéndose una valoración en tres niveles: primordial (AmC con una participación mínima del $20 \%$ de la docencia del BMC que correspondiese), básico (mínimo del $10 \%$ ), y opcional (no deben sobrepasar un $10 \%$ ).

En cuanto al peso proporcional asumido por cada BMC dentro del título, el Libro Blanco, a partir del consenso entre los diversos agentes consultados para su elaboración, planteaba una propuesta en la que el peso total atribuido a los tres BMC de más patente proyección territorial superaba el $40 \%$ del total: Fundamentos y dimensiones del turismo (14,09\%), Recursos y productos turísticos (14,24\%), y Destinos Turísticos (12,97\%). El Cuadro 1 muestra los contenidos que el Libro Blanco define para estos tres BMC, incluyendo las competencias a desarrollar y las complementarias ${ }^{2}$.

Cada BMC establece así un contenido común. Con todo, la flexibilidad apuntada párrafos atrás se refleja en el hecho de que es competencia de las universidades perfilar posteriormente las asignaturas concretas en que se articulan los diversos BMC, teniendo potestad asimismo para seleccionar las áreas de conocimiento que se encargarán de su impartición (de entre las previstas en los AmC vinculados a cada BMC). Así, cada una puede configurar su plan de estudios, siempre y cuando se cumplan los objetivos formativos especificados por cada una de las competencias asignadas al BMC.

En el caso de la dimensión territorial del turismo, el Cuadro 1 sirve para constatar que los tres BMC definidos muestran una clara interrelación de contenidos, lo que ha contribuido a la heterogeneidad que evidencia el diseño de los distintos planes de estudio del Grado de Turismo. Pese a esto, el análisis detenido de varios de ellos permite reconocer rasgos comunes en una serie de asignaturas básicas y obligatorias que, aunque con diferencias en la denominación y la organización específica, coinciden en lo esencial con la estructura temática de geografía del turismo, recursos territoriales turísticos, y ordenación, planificación y gestión del territorio turístico (Cuadro 2).

2 Las competencias complementarias son las asignadas a otro BMC pero que en el BMC en cuestión buscan una aplicabilidad determinada. 


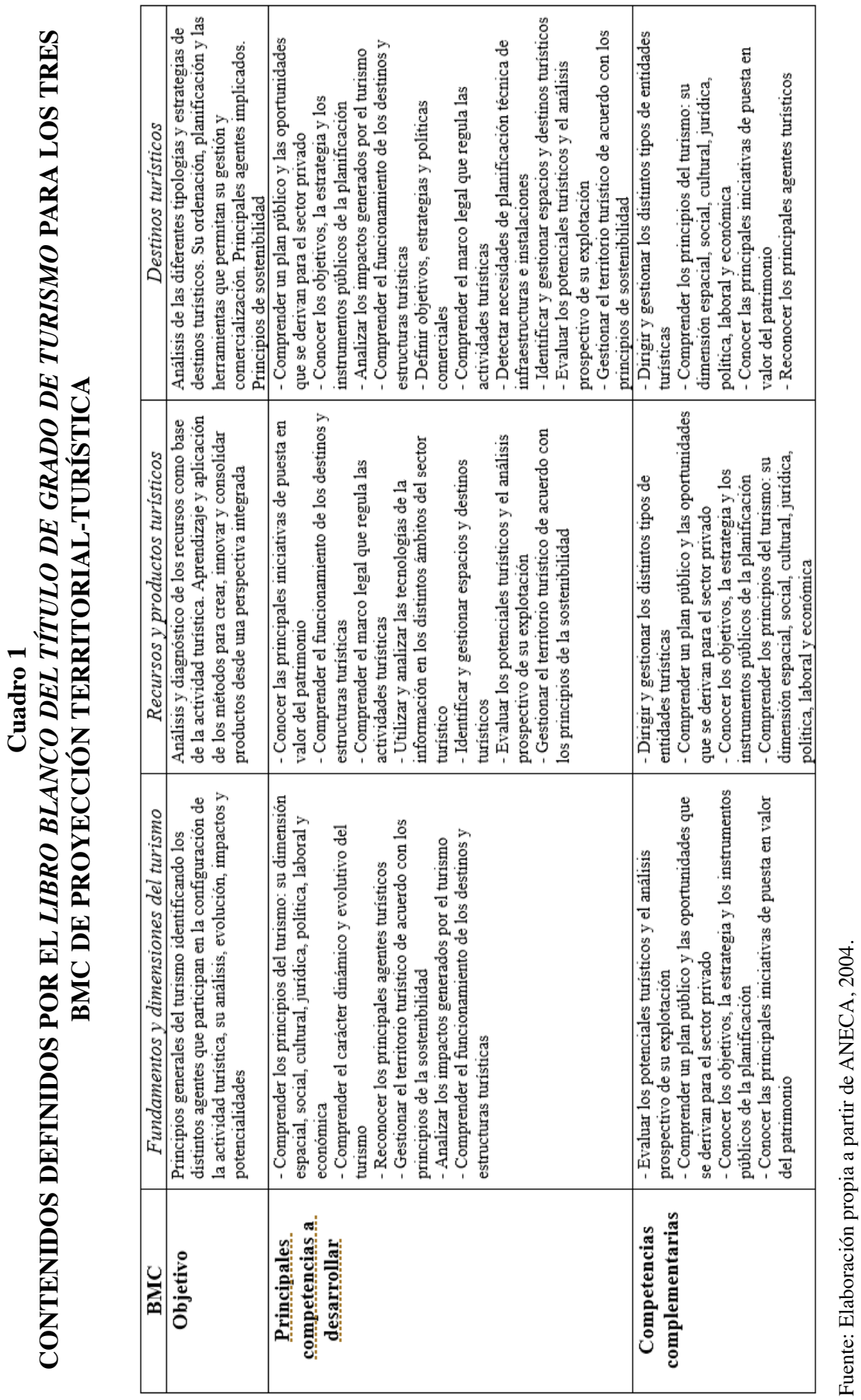




\section{Cuadro 2}

\section{ESTRUCTURACIÓN DE LOS ESTUDIOS TERRITORIALES EN LOS GRADOS DE TURISMO EN VARIAS UNIVERSIDADES ESPAÑOLAS}

\begin{tabular}{|c|c|c|c|}
\hline Universidad & Asignatura & Carácter & Curso \\
\hline \multirow[t]{4}{*}{ Alicante } & Introducción a la Geografia del Turismo & Básica & 1 \\
\hline & Recursos Territoriales Turísticos & Básica & 1 \\
\hline & Tipologías de los Espacios Turísticos & Obligatoria & 2 \\
\hline & Planificación Territorial del Turismo & Obligatoria & 3 \\
\hline \multirow[t]{3}{*}{ Barcelona } & Geografia del Turismo & Básica & 1 \\
\hline & Patrimonio y Turismo & Básica & 2 \\
\hline & Análisis de los Destinos Turísticos & Obligatoria & 3 \\
\hline \multirow{3}{*}{$\begin{array}{l}\text { Complutense de } \\
\text { Madrid }\end{array}$} & Geografia del Turismo & Básica & 1 \\
\hline & Patrimonio Territorial, Flujos y Recursos Turísticos & Obligatoria & 2 \\
\hline & Planificación de Destinos Turísticos & Obligatoria & 2 \\
\hline \multirow[t]{3}{*}{ Córdoba } & Geografia del Turismo & Básica & 1 \\
\hline & Recursos Territoriales Turísticos & Básica & 2 \\
\hline & Planificación y Ordenación Turística del Territorio & Obligatoria & 3 \\
\hline \multirow[t]{5}{*}{ Murcia } & Recursos Territoriales Turísticos & Básica & 1 \\
\hline & Turismo Sostenible y Medio Ambiente & Obligatoria & 1 \\
\hline & Ordenación de los Espacios Turísticos & Obligatoria & 2 \\
\hline & Gestión de Destinos Turísticos & Obligatoria & 3 \\
\hline & Creación de Productos Turísticos & Obligatoria & 4 \\
\hline
\end{tabular}

Fuente: Publicación de los planes de estudio (BOE). Elaboración propia.

Con todo, el examen minucioso de los contenidos temáticos de tales asignaturas (realizado mediante el manejo de las respectivas Memorias de Verificación de los planes de estudio, así como de las Guías Docentes de las asignaturas concernidas) confirma una situación de acusada disparidad, e incluso de contradicción, entre las facultades que las imparten. Ello es, particularmente evidente en lo relativo a la delimitación entre los aspectos conceptuales y de fundamento de la dimensión territorial del turismo, por una parte, y los más propiamente descriptivos, alusivos a los grandes tipos de espacios, flujos y dinámicas, por otra. La consideración indistinta y heterogénea entre planes de ambos bloques de cuestiones, tanto en las asignaturas de Geografía del Turismo como en las de Recursos Territoriales Turísticos (o de denominación similar), exige una clarificación, que pueda contribuir a una equiparación de mínimos entre universidades, en consonancia con lo establecido al respecto en el Libro Blanco del Grado de Turismo y en los BMC definidos en él.

En este sentido, se ofrece una propuesta que estimamos coherente y que se viene desarrollando con éxito en el centro de los autores que esto suscriben (Cuadro 3). A nuestro juicio, Recursos Territoriales Turísticos puede asumir un carácter eminentemente analítico, conceptual y explicativo de la vertiente territorial del turismo, abordando el estudio de los recursos como factor primordial del mismo. Sobre esta base, la Geografía del Turismo (o asignaturas de denominación equivalente) podrían adoptar un enfoque más descriptivo, considerando las grandes dinámicas del desarrollo turístico. 
Tras ello, la Planificación del Territorio Turístico abordaría los procesos específicos de ordenación y gestión en los diversos tipos de destinos.

\section{Cuadro 3 \\ CUESTIONES CLAVE EN EL ESTUDIO DE LA DIMENSIÓN TERRITORIAL DEL TURISMO Y PROPUESTA DE ESTRUCTURACIÓN EN ASIGNATURAS PARA SU CONSIDERACIÓN}

\begin{tabular}{|l|c|c|}
\hline \multicolumn{1}{|c|}{ Cuestiones clave a considerar } & $\begin{array}{c}\text { Propuesta de asignatura } \\
\text { (denominaciones } \\
\text { aproximadas) }\end{array}$ & $\begin{array}{c}\text { Propuesta } \\
\text { de curso }\end{array}$ \\
\hline $\begin{array}{l}\text { - Fundamentos de la relación turismo-territorio } \\
\text { - Factores de localización turística: el papel de los } \\
\text { recursos } \\
\text { - Tipos de recursos y herramientas para su } \\
\text { conocimiento } \\
\text { - Función turística: creación de productos y oferta } \\
\text { - Conceptualización de destino y región turística }\end{array}$ & Recursos Territoriales Turísticos & $1^{\circ}$ \\
\hline $\begin{array}{l}\text { - Distribución geográfica de la actividad turística } \\
\text { a distintas escalas: principales magnitudes } \\
\text { - Principales tipos de destinos turísticos } \\
\text { - Análisis detallado de destinos turísticos por } \\
\text { grandes conjuntos regionales }\end{array}$ & Geografia del Turismo & $2^{\circ}$ \\
\hline $\begin{array}{l}\text { - Territorio turístico: componentes específicos y } \\
\text { diversidad de situaciones } \\
\text { - Ordenación de Territorio: fundamentos básicos y } \\
\text { aplicación al turismo } \\
\text { - Instrumentos para la planificación y gestión del } \\
\text { territorio turístico }\end{array}$ & Planificación del Territorio \\
\hline $\begin{array}{l}\text { - Aspectos más específicos relativos a destinos } \\
\text { turísticos y su gestión }\end{array}$ & Turístico & \\
\hline
\end{tabular}

Fuente: Elaboración propia a partir de Almirón, 2004; Barrado, 2004; Barrado y Ávila, 2010; García y Pérez, 2008; López, 1998; Lozato-Giotart, 1990; Simancas, Coord., 2016; Vera, Coord., 2014.

\section{PROPUESTA DE DESARROLLO CONCEPTUAL Y METODOLÓGICO PARA LA ASIGNATURA RECURSOS TERRITORIALES TURÍSTICOS}

Una vez justificada la pertinencia (más aún, la indudable necesidad) de la aproximación geográfica al fenómeno turístico, revisadas las líneas con las que los trabajos sobre la materia se han incorporado al currículum universitario en nuestro país y explicado y justificado el modo en el que la asignatura Recursos Territoriales Turísticos puede insertarse de manera coherente en el plan de estudios del Grado de Turismo, parece obligado hacer una propuesta propia sobre el modo en que abordar sus contenidos. Y ello apoyado en un recorrido ya relativamente dilatado de la enseñanza de la materia en el que los autores han sido responsables de su impartición durante varios cursos académicos, lo cual permite aprovechar la práctica adquirida para fundamentar planteamientos y metodologías a partir 
de experiencias contrastadas, pero, al mismo tiempo, constatar la necesidad de mantener posturas abiertas ante una disciplina no definitivamente configurada, con ideas todavía necesitadas de una mayor concreción.

\subsection{Recorrido conceptual: del territorio a los recursos y al destino turístico}

El carácter principalmente conceptual y cimentador del análisis geográfico del turismo asumido por la asignatura explica que su docencia se haya organizado en torno a una serie de nociones e ideas básicas, claramente secuenciadas entre sí, que perfilan una suerte de recorrido en relación con el cual, de una manera didáctica y comprensiva para el alumnado, se pone especial énfasis en la interrelación.

El punto de partida para ello es la visión sistémica del turismo, es decir, el entendimiento del fenómeno como una realidad compleja y dinámica, resultante de la interacción de diversos componentes. Así, a partir de las diferentes aproximaciones al sistema turístico recogidas en la bibliografía especializada (López, 1998; Vera, Coord., 2014), se ofrece una propuesta metodológica de síntesis y se observan las relaciones entre los elementos esenciales (Figura 1) a modo de encuadre donde abordar el estudio de la dimensión territorial del mismo.

\section{Figura 1 \\ SISTEMATIZACIÓN METODOLÓGICA DEL SISTEMA TURÍSTICO DESDE UNA APROXIMACIÓN TERRITORIAL AL MISMO}

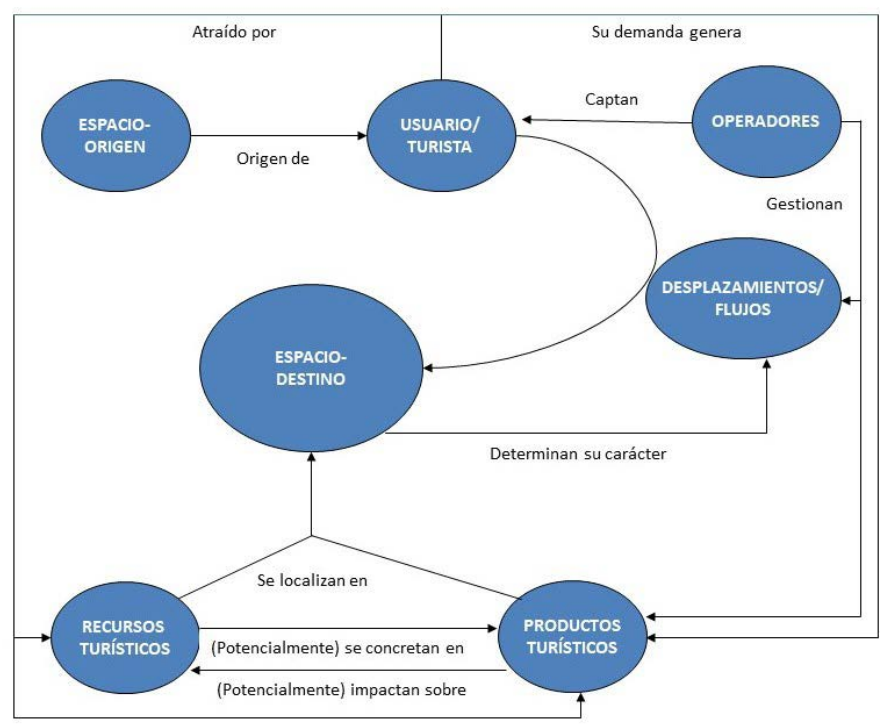

Fuente: Elaboración propia a partir de Lozato-Giotart, 1990; Cooper y otros, 2007; Vera, Coord., 2014; Vera y Baños, 2016. 
En efecto, a partir de los que se proponen como los grandes componentes del sistema turístico (usuarios, operadores, flujos, espacio, recursos y productos), son los tres últimos los que sustentan mayormente el recorrido conceptual pergeñado para la asignatura. Sobre esta base, la territorialidad del turismo se concibe como la vinculación ineludible de la actividad a un espacio determinado, a partir de la proyección y concreción física en él (Vera, Coord., 2014); una relación enmarcada en el contexto de la estrecha y continua interacción entre esta y el marco que la acoge (Figura 2), cuyas claves se tratan de exponer de manera didáctica y visual al alumnado.

\section{Figura 2 \\ PROPUESTA SINTÉTICA PARA LA COMPRENSIÓN DE LA INTERACCIÓN TERRITORIO-TURISMO}

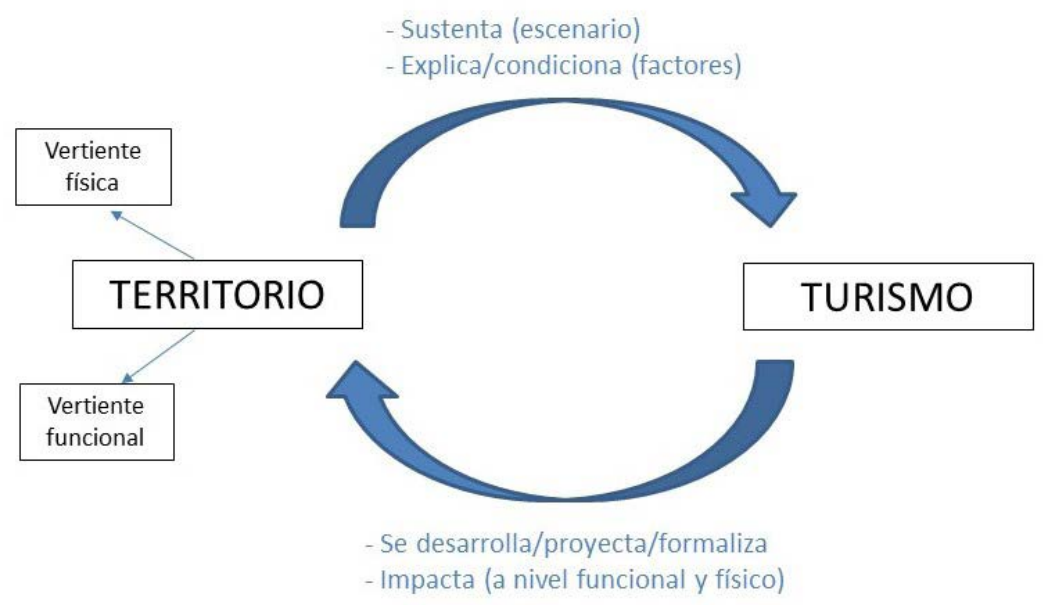

Fuente: Elaboración propia.

Es por ello por lo que el espacio geográfico, en tanto que asiento imprescindible para los procesos naturales y humanos, constituye el primer hito del recorrido propuesto. La idea a remarcaren este punto es que, como se ha venido apuntando, el turismo siempre se desarrolla, localiza y formaliza sobre un ámbito físico determinado. Este conforma un soporte material que, lejos de ser neutro, presenta características propias, específicas y diferentes a las de otros lugares, que configuran el marco percibido y, en su caso, estimado por la demanda (Urry, 1996 recogido por Almirón, 2004). De aquí se infiere directamente el concepto de territorio, con el cual se identifica al espacio adscrito a una comunidad que aparece como su escenario de vida, el soporte básico de su actividad y su referente en la memoria individual y colectiva (Zoido, 1998). Con unos límites definidos y reconocibles, de carácter físico y/o administrativo, el territorio es, pues, un espacio humanizado en el que el grupo social que lo ocupa encuentra sus señas de identidad y afianza su sentimiento de pertenencia, al tiempo que lo impregna de valores culturales y lo transforma de forma 
continua de acuerdo con la evolución de las dinámicas que desencadena sobre él (Ortega, 1998; Cañizares, 2009; Vargas, 2012).

En su expresión visual, este se manifiesta a través del paisaje, que no es sino la plasmación formal de las complejas interrelaciones que existen entre los elementos naturales y culturales subyacentes, así como de los procesos ecológicos y socioeconómicos que se desarrollan sobre ellos (Mata, 2006).Pero, además - tal y como se recoge en la conocida definición del Convenio Europeo del Paisaje 3 - el término conlleva un inevitable componente de percepción a través del cual es interpretado y apreciado por la población. Así pues, cualquier parte del territorio es paisaje y como tal constituye "un bien colectivo que mantiene la memoria de los grupos sociales, refleja la evolución social y cultural de las comunidades y constituye un elemento primordial en la identidad de los pueblos" (Becerra, 2005, 73).

Desde esta perspectiva, es evidente que territorio y paisaje se insertan con pleno derecho dentro del ámbito de lo que actualmente se considera patrimonio, ya que se trata de realidades que devienen de la histórica relación dialéctica entre el ser humano y el medio. Este, como afirma Roch $(1998,80)$, tiene "capacidad acumulativa y de conservar la memoria", permitiendo por ello proporcionar una amplia información sobre los grupos que lo han habitado. Por tanto, pueden calificarse como tales aquellos elementos que, por sus contenidos y sus significados, constituyen referentes identitarios incuestionables para la sociedad que los construye y los vive, y que, por todo ello, son merecedores de ser preservados como parte de la herencia común que debe ser transmitida a las generaciones futuras (Florido, 2013). Estos contenidos son los que soportan la noción, algo más específica, de patrimonio territorial, de aparición relativamente reciente pero cada vez más utilizada en el análisis geográfico ${ }^{4}$ y en la práctica planificadora. Dentro de él quedan integrados todo tipo de bienes y espacios, tanto naturales como culturales que, por su carácter identitario para la población, gocen de un interés intrínseco susceptible de ser reconocido y protegido mediante instrumentos específicamente concebidos para ello (Mata, 2006; Jiménez, Dir., 2009; Cañizares, 2009; Florido, 2013).

Además, el patrimonio, con su rasgo esencial de legado e identidad socio-territorial, puede llegar a conformarse como un recurso, como un elemento generador de beneficios "en la medida que es un bien cultural heredado y aceptado socialmente al poseer un valor simbólico para una determinada población"; e incluso como "recurso económico por cuanto es un bien escaso y no renovable dotado de un valor de uso y de cambio que se puede convertir en objeto de consumo" (Cañizares, 2009, s.p. siguiendo a Ortega, 1998). En concreto, su percepción como atractivo, susceptible de generar un determinado tipo de experiencia de ocio, es capaz de perfilarlo como recurso turístico.

De esta manera, pese a la variedad de visiones y definiciones existentes en torno al concepto (Arnandis, 2019), parece claro que se trata de bienes dotados de una valía o singularidad intrínseca, de ahí que la asignatura parta de la premisa de que los recursos turísticos tienen mayoritariamente un fundamento patrimonial previo (Jiménez, Dir., 2009). Por otra parte, la totalidad de los recursos se vinculan de una u otra manera a un territorio en el que

3 "Por paisaje se entenderá cualquier parte del territorio tal como la percibe la población, cuyo carácter sea el resultado de la acción y la interacción de factores naturales y/o humanos" (Consejo de Europa, 2000, art. 1).

4 Vid., entre otros, Ortega, 1998; Mata, 2006; Silva, 2008; Silva y Fernández, 2008; Cañizares, 2009; Castillo, 2009; Florido, 2013; Troitiño y Troitiño, 2018. 
se hacen accesibles; pero, de acuerdo con López (1998), por recursos territoriales turísticos entendemos solo los concretados físicamente en un lugar determinado y que están indisolublemente ligados a él. Precisamente por ello son estos nuestro objeto de atención específica.

La noción de recurso turístico se basa, pues, en la posibilidad de desarrollar una experiencia de ocio centrada en el reconocimiento específico de tales bienes de base patrimonial (una práctica turística, en suma), el cual les permite asumir un sesgo ciertamente diferenciado, según la naturaleza del recurso y la motivación de los potenciales usuarios: desde la contemplación y el goce escénico, al contacto directo e interpretación en detalle, o el uso lúdico activo o deportivo (Ortega, 1998).En esta línea, la docencia propuesta remarca la idea de que, como vienen afirmando diversos autores, incluso más que sus atributos intrínsecos, serán los procesos de valorización social los que determinarán qué elementos se convertirán en recursos reales, en uso, es decir, en verdaderos atractivos y, por lo tanto, en efectivos agentes de desarrollo (Almirón, 2004; Barrado y Ávila, 2010; Barrado, 2011; Navarro, 2015) (Figura 3).

Los recursos territoriales turísticos se presentan, pues, en la asignatura como el principal factor (aunque no único) explicativo de la actividad en un espacio dado. Pero, para hacerla posible, resulta imprescindible adaptarlos a este uso, lo cual genera una nueva realidad, el producto turístico, en el que el recurso aparece acondicionado para lograr la satisfacción del viajero.

La funcionalidad turística de los recursos viene dada por una serie de requisitos básicos que se sintetizan en tres fundamentales:

- El reconocimiento por parte de la demanda de la existencia de un elemento o espacio de interés evidente (más allá del valor patrimonial intrínseco).

- Una adecuación in situ que cree las condiciones mínimas para la apertura al público y posibilite una cierta afluencia de visitantes (aunque las casuísticas en cada caso serán diferentes); y, por supuesto, la decidida participación de agentes públicos y privados que lo impulsen a través de actuaciones precisas de diseño, promoción y comercialización (Ávila y Barrado, 2005; Antón y González, 2007).

- Si el cumplimiento de los dos requisitos anteriores ya permite constatar una funcionalidad turística en el recurso, esta alcanzará su máxima expresión cuando se produzca su plena integración en el contexto territorial en que se encuentra. Y ello tiene lugar a través de la interacción con los equipamientos y servicios existentes y con los demás atractivos del entorno, de su consideración en las campañas de imagen y promoción del destino y, en definitiva, de su total inserción en la realidad física, sociocultural y económica del espacio de acogida (Vera, Coord., 2014).

Evidentemente, la funcionalización de los recursos conlleva su inclusión en el mercado turístico, con las consiguientes posibilidades de explotación y comercialización dentro de un sector en el que la competencia es cada vez mayor y donde la mercadotecnia territorial se convierte en una herramienta de posicionamiento indispensable (Lois, 2008), siendo un hecho que "el uso recreativo y la función turística [...] ponen de manifiesto que el consumo de ocio está vinculado a la mercantilización del patrimonio" (Hewisona, 1987, citado por Antón y otros, 2008, 10). 
Figura 3

PROPUESTA DE RELACIÓN EPISTEMOLÓGICA ENTRE LOS CONCEPTOS CLAVES PARA LA ASIGNATURA RECURSOS TERRITORIALES TURÍSTICOS

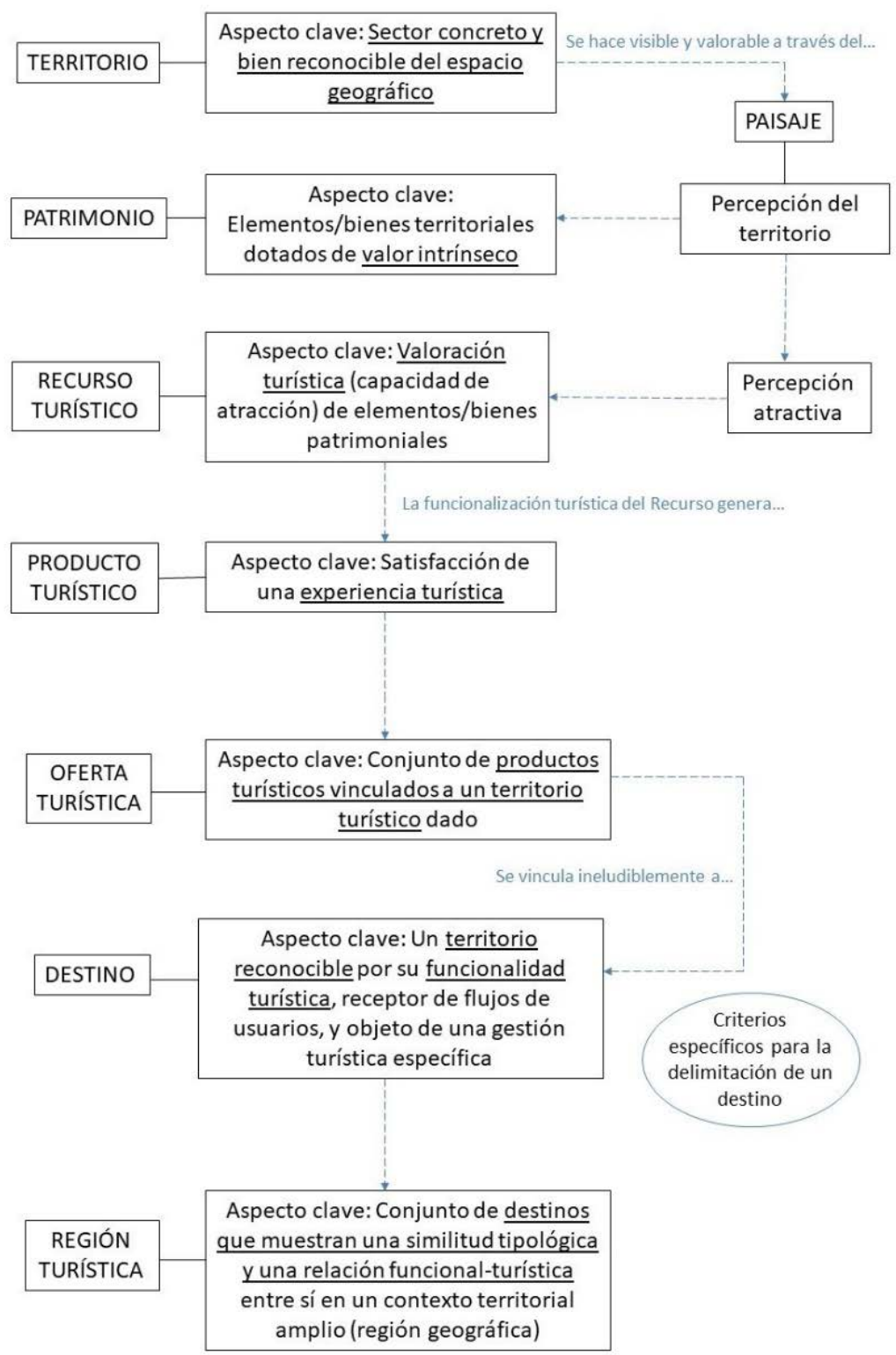

Fuente: Elaboración propia a partir de Barrado, 2004; Barrado y Ávila, 2010; Cañizares, 2009; Díaz, 2011; Mata, 2008; Silva y Fernández, 2008; Simancas, Coord., 2016; Vera, Coord., 2014. 
La ligazón de los productos con una determinada base geográfica conduce al concepto de oferta turística (Vera, Coord., 2014). La oferta comprende los recursos y productos de los que el visitante puede disfrutar en un marco territorial dado, pero también las imágenes que los identifican, publicitan y promocionan, así como las estrategias de comunicación y distribución con las que hacerlas llegar al usuario y el precio de venta de lo ofrecido, todos ellos aspectos esenciales para incitarlo a decantarse por una determinada propuesta. El objetivo último es definir una experiencia turística completa, que reproduzca lo más fielmente posible los caracteres definitorios del territorio, pero que también responda de manera satisfactoria a los requerimientos de la demanda. A tenor de lo dicho, la oferta resulta inseparable del destino turístico en el que esta se concreta y donde, finalmente, se realiza la actividad.

La definición y caracterización del destino también constituyen materias repetidamente abordadas por los especialistas, conscientes de que se trata de un concepto y herramienta clave para los procesos de ordenación y gestión de los ámbitos turísticos, pero asimismo de difícil concreción (entre otros, vid. Hiernaux-Nicolás, 1994; Barrado, 2004; Ávila y Barrado, 2005; OMT, 2005; Ejarque, 2005; Galiana y Vinuesa, 2006; Coopery otros, 2007; Antón y otros, 2007; López Bonilla, 2007; Barrado y Ávila, 2010; Vera, Coord., 2014; Vera y Baños, 2016, etc.).Lugar de localización de los recursos y productos, el destino es descrito como un espacio definido y reconocible, Fundamentalmente, por su uso turístico, en el cual dicha función se convierte en componente predominante (o, al menos, altamente significativo) del sistema territorial y socioeconómico. Aunque su delimitación precisa no es fácil, el manejo de la bibliografía especializada, el análisis de casos y la reflexión subsiguiente nos han permitido señalar una serie de criterios básicos para dicha delimitación, que se exponen de manera sistemática al alumnado durante el desarrollo de la docencia.

- Un primer criterio para poder hablar de su existencia alude a la adecuación formal y funcional del espacio para dar respuesta a las necesidades y demandas de los visitantes a través de una amplia oferta de atractivos, servicios y equipamientos; dicho de otro modo, la existencia de una oferta temáticamente singularizable, bien estructurada, referenciada territorialmente y promocionada de forma conjunta.

- A raíz de lo anterior, un segundo requisito se centra en la afluencia de corrientes turísticas de forma más o menos constante (con independencia de la intensidad de dichos flujos y de la escala de procedencia de los mismos), lo que es reflejo de la existencia de un espacio turístico identificable como tal por la demanda.

- A ello contribuye asimismo la existencia de una imagen asociada al territorio, a sus rasgos definitorios y su patrimonio, que se proyecte turísticamente, y que no solo contribuya a su singularización, sino que también otorgue un particular significado simbólico a los productos ofrecidos.

- Un cuarto y último criterio alude al destino como espacio sujeto a una ordenación y gestión específicas orientadas a la organización y promoción de su oferta, la adecuación de la misma a la base geográfica y patrimonial, y la satisfacción de la demanda (Pearce, 2014). Su consideración como marco de ordenación territorial tiene a su vez una significativa incidencia en otro aspecto tan relevante como es 
la escala de definición. No hay duda de que el concepto, con una orientación promocional, se ha empleado en sentido amplio para aludir a ámbitos de escalas muy diversas; sin embargo, la aplicación de una visión operativa requiere su necesaria definición y delimitación a otras mayores (principalmente, municipal y subregional), adaptadas a la ordenación emanada de los instrumentos de planificación y a las decisiones de gestión.

Así pues, el destino se asimila a un entorno construido a partir de resoluciones económicas y de determinaciones de carácter espacial, configurándose al mismo tiempo como objeto de producción y consumo turístico y como ámbito de ordenación territorial; por lo tanto, es un área bien reconocible por la demanda, con límites definidos con claridad y dotada de una serie de componentes básicos que, en su conjunto y en su interrelación, pueden ser considerados como un sistema territorial (del cual se hablará en el siguiente epígrafe).

Finalmente, de ello se deriva una última noción clave para la asignatura, la de región turística, término un tanto impreciso desde el punto de vista de su empleo para el estudio de la actividad en la medida en que con él se hace referencia a realidades de muy distinta naturaleza - hasta el punto de identificarlo ocasionalmente con el de destino (Lozato-Giotart, 1990) — , pero muy interesante para la adecuada comprensión y planificación de la práctica turística en el momento actual. Entendida como una forma espacial compleja formada por una agregación de destinos y sus respectivas áreas de influencia, de la que deriva una dinámica funcional en forma de sinergias o interacciones turísticas, sobre todo en forma de flujos de usuarios (Gunn, 1994; Simancas, Coord., 2016), presenta unos límites reconocibles (ya que los destinos que la integran gozan, por lo general, de rasgos culturales, sociales o físicos similares u homogéneos) que generan identidad regional.

\subsection{Planteamientos y herramientas docentes y metodológicas}

En coherencia con lo expuesto en el apartado precedente, fundamento epistemológico de la materia, en este se explica el desarrollo específico de la docencia. Se abordan, por tanto, facetas más concretas de contenido relativas a las ideas referidas, pero también se sintetizan los aspectos procedimentales y metodológicos.

La asignatura se estructura en cinco temas articulados según una secuencia considerada lógica en función de dos criterios primordiales: el recorrido conceptual referido y la imprescindible articulación de conocimientos teóricos, prácticos y de índole más propiamente instrumental y aplicada (Cuadro 4).

Es en el primer tema donde se explica la complejidad característica del fenómeno turístico - que permite considerarlo como un sistema - así como su inexcusable interacción con el entorno geográfico. Precisamente, el aspecto nuclear que subyace a lo largo de todo el temario radica en tratar de entender en sus dimensiones básicas la proyección territorial de la función turística a partir del desencadenante esencial constituido por los factores de atracción.

En efecto, para el análisis del territorio turístico se hace hincapié, con un sentido metodológico y didáctico, en lo que se entiende como un ineludible doble plano de apro- 
ximación: el funcional (relativo a los procesos, las dinámicas, las funciones — naturales o antrópicas - ), y el físico (la base formal o morfológica de dichos procesos y funciones, en parte resultado de ellas, pero a su vez explicativa de las mismas). El estudio de este ha de realizarse necesariamente con un planteamiento amplio que considere los elementos naturales, pero también los que derivan de la relación del ser humano con el medio, es decir, los antrópicos y culturales, ya que será la conjunción de todos ellos la que permitirá el entendimiento del espacio que soporta y genera la actividad y que continuamente es transformado por ella. Por su parte, el examen del plano funcional es indispensable para conocer los aspectos asociados al desarrollo y la dinámica del turismo. Las conexiones e interacciones existentes entre ambos planos, así como su permanente evolución mostrarán la complejidad del sistema turístico en toda su amplitud, resultando de gran utilidad metodológica a lo largo de todo el temario.

\section{Cuadro 4 \\ PROPUESTA DE ORGANIZACIÓN DE TEMARIO PARA LA ASIGNATURA RECURSOS TERRITORIALES TURÍSTICOS}

\begin{tabular}{|c|c|}
\hline $\begin{array}{l}\text { Tema 1. Introducción: los recursos en el } \\
\text { marco del análisis territorial del turismo }\end{array}$ & $\begin{array}{l}\text { 1.1. El turismo como fenómeno complejo y } \\
\text { territorial: el sistema turístico } \\
\text { 1.2. Esquema conceptual para el estudio de los } \\
\text { recursos territoriales turísticos }\end{array}$ \\
\hline $\begin{array}{c}\text { Tema 2. Los recursos territoriales } \\
\text { turísticos: conceptualización y } \\
\text { clasificación }\end{array}$ & $\begin{array}{l}\text { 2.1. Los recursos turísticos y los recursos } \\
\text { territoriales turísticos } \\
\text { 2.2. Clasificación de los recursos territoriales } \\
\text { turísticos }\end{array}$ \\
\hline $\begin{array}{c}\text { Tema 3. Los factores de localización } \\
\text { turística }\end{array}$ & $\begin{array}{l}\text { 3.1. Los factores de localización: concepto y tipos } \\
\text { 3.2. Factores posicionales } \\
\text { 3.3. Factores ambientales } \\
\text { 3.4. Otros factores (no territoriales) }\end{array}$ \\
\hline $\begin{array}{l}\text { Tema 4. La catalogación de los recursos } \\
\text { territoriales turísticos }\end{array}$ & $\begin{array}{l}\text { 4.1. La importancia de la catalogación de los } \\
\text { recursos } \\
\text { 4.2. La catalogación: pasos y herramientas } \\
\text { metodológicas }\end{array}$ \\
\hline $\begin{array}{c}\text { Tema 5. Producto turístico y destino } \\
\text { turístico. }\end{array}$ & $\begin{array}{l}\text { 5.1. La turistización de los recursos territoriales: } \\
\text { la funcionalidad turística } \\
\text { 5.2. Producto turístico y.oferta turística } \\
\text { 5.3. Destino: definición y criterios de delimitación } \\
\text { 5.4. Destino y sistema territorial turístico } \\
\text { 5.5. Región turística }\end{array}$ \\
\hline
\end{tabular}

Fuente: Elaboración propia.

El tema 2 se centra específicamente en los recursos. La distinción entre recurso turístico (actividad o elemento dotado de valor intrínseco o patrimonial y contemplado como potencialmente turístico) y recurso territorial turístico (recurso turístico que, además de estar localizado en un territorio, asume una concreción física obligada y permanente en él) resulta fundamental en este punto, siendo ilustrada al alumnado mediante ejemplos significativos que se explican y trabajan en el aula (Figura 4). 


\section{Figura 4 \\ UNO DE LOS EJEMPLOS EMPLEADOS PARA DELIMITAR EL CONCEPTO DE RECURSO TERRITORIAL TURÍSTICO}

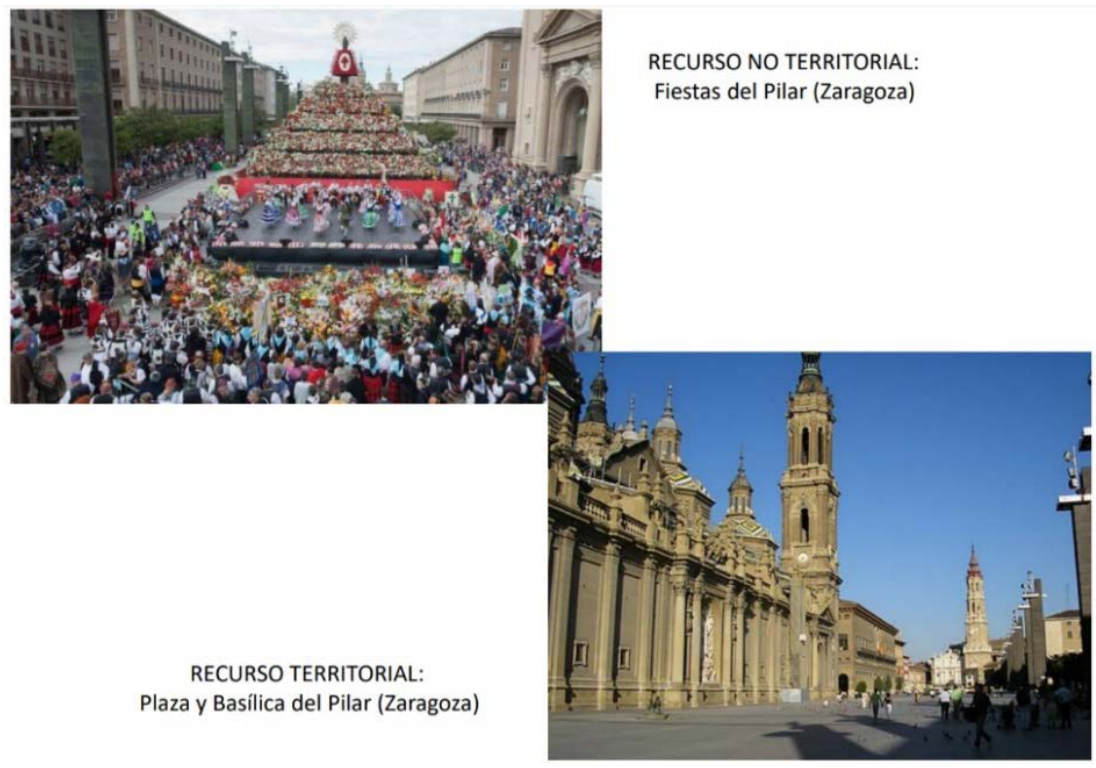

Fuente: Elaboración propia.

Tras esta delimitación conceptual, se remarca que los recursos, en tanto que factores de atracción primordial, contribuyen decisivamente a explicar el sesgo asumido por la actividad. Planteamos así una propuesta de tipologías turísticas (Figura 5), es decir, de diferentes formas de hacer turismo según sea la base territorial y sus recursos, en confluencia con la iniciativa y decisiones tanto de los agentes turísticos como de los usuarios. A partir del manejo bibliográfico y la reflexión, se trata de hacer pensar al alumnado ante la frecuente confusión que suele observarse en torno a esta cuestión, particularmente al hablar de grandes tipologías de difícil delimitación y concreción espacial (como el turismo cultural o el de naturaleza) o de otras muy cuestionables en cuanto a su carácter, como el turismo residencial o el de negocios. Quedan así definidos unos grupos básicos (grandes tipos de experiencias turísticas) que, sin duda, pueden incorporar subtipos o modalidades más específicas; tal sería, por ejemplo, el turismo de compras o el de congresos en el marco de una realidad más amplia como el turismo urbano, centrado en la toma de contacto con la dinámica y el paisaje de la ciudad.

El trabajo práctico en relación con esta cuestión se centra en plantear al alumnado, organizado en grupos de trabajo de dos-tres estudiantes, la búsqueda de ejemplos de territorios turísticos definidos por situaciones tanto de mono funcionalidad turística (una tipología turística exclusiva, aún con varios subtipos) como de multifuncionalidad turística (donde convivan diversas tipologías turísticas, que puedan llegar a complementarse entre sí). 


\title{
Figura 5 \\ PROPUESTA DE SISTEMATIZACIÓN DE GRANDES TIPOLOGÍAS TURÍSTICAS A PARTIR DE LA BASE TERRITORIAL
}

\author{
RECURSOS TERRITORIALES \\ (Carácter)
}

TIPOLOGÍAS TURÍSTICAS

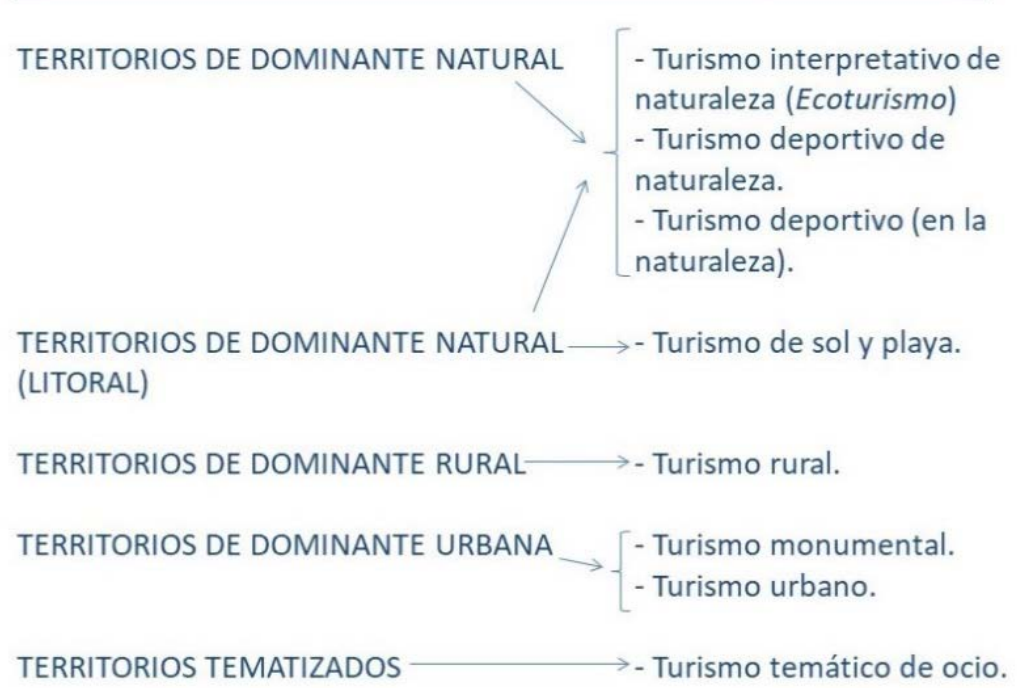

Fuente: Elaboración propia a partir de Almirón, 2004; Silva y Fernández, 2008; Simancas, Coord., 2016; Vera, Coord., 2014.

El análisis y ejemplificación más detallada de los recursos territoriales turísticos es llevado a cabo mediante su clasificación. Para esta se proponen diferentes criterios complementarios entre sí (Cuadro 5) que provienen de la profusa bibliografía manejada y que presentamos ordenadamente. En primer lugar, se consideran dos de carácter físico: el origen (natural, antrópico y mixto - es decir, de raíz natural, pero decisivamente modificado por la intervención humana-), y el valor patrimonial o intrínseco (establecido a partir de las categorías y figuras de reconocimiento y protección a diversas escalas, los cuales, en muchos casos, refuerzan el atractivo de los bienes). Tras estos dos primeros criterios, un tercero combina el carácter físico y la dimensión funcional-turística: nos referimos a la conexión establecida entre la formalización territorial (relativa a la extensión o superficie ocupada por un determinado recurso) y el tipo de experiencia generada. En este sentido, cabe distinguir entre recursos puntuales (elementos concretos y muy bien localizables en el espacio, generadores de una experiencia singular) y zonales (ámbitos relativamente extensos, pero dotados de homogeneidad interna, que pueden sustentar prácticas turísticas variadas). Los dos últimos criterios resultan netamente funcionales, es decir, aluden directamente a la cuestión turística y no tanto a la base física ya que hacen referencia respecti- 
vamente al papel asumido por esta función en el recurso (principal, secundaria, incidental o inexistente) y a la capacidad de atracción de estos respecto de otros del mismo territorio (distinguiéndose entre básicos — con capacidad de atracción propia - y complementarios).

La explicación de las tipologías de recursos se completa con un trabajo de carácter práctico donde los estudiantes, en los pequeños grupos de trabajo conformados, deben clasificar, empleando los diferentes criterios manejados, los principales recursos territoriales turísticos localizados en los ámbitos con los que trabajaron previamente la cuestión de las tipologías turísticas.

\section{Cuadro 5 \\ CRITERIOS PROPUESTOS PARA LA CLASIFICACIÓN DE LOS RECURSOS TERRITORIALES TURÍSTICOS}

\begin{tabular}{|c|c|}
\hline \multicolumn{2}{|l|}{ Criterio de clasificación } \\
\hline \multirow{3}{*}{ Origen } & Natural \\
\hline & Antrópico \\
\hline & Mixto \\
\hline $\begin{array}{c}\text { Reconocimiento/protección del valor intrínseco del } \\
\text { patrimonio natural y cultural }\end{array}$ & $\begin{array}{l}\text { Reconocimientos a } \\
\text { escala internacional, } \\
\text { nacional, autonómica y } \\
\text { local }\end{array}$ \\
\hline \multirow{2}{*}{$\begin{array}{l}\text { Formalización y proyección territorial en relación } \\
\text { con la experiencia turística }\end{array}$} & Puntual \\
\hline & Zonal \\
\hline \multirow{4}{*}{ Relevancia del uso turístico } & Principal \\
\hline & Secundario \\
\hline & Incidental \\
\hline & Inexistente \\
\hline \multirow{2}{*}{ Grado de funcionalidad turística } & Básico \\
\hline & Complementario \\
\hline
\end{tabular}

Fuente: Elaboración propia a partir de Cañizares, 2009; Leno, 1991; 1993; López, 1998; MINCETUR, 2006; 2018; OMT, 2013; Simancas, Coord., 2016.

Los recursos turísticos constituyen el componente imprescindible de atracción. Sin embargo, no son suficientes para responder a la cuestión de la localización (dónde) y carácter (cómo) de la actividad en su proyección territorial. También resultan decisivos al respecto los factores de localización, objeto de consideración del tema 3.

Siguiendo a Vera (Coord., 2014) - que, a su vez, recoge parte de los planteamientos de Butler (1986) - , cabe decir que estos pueden actuar en un sentido positivo (como facilitadores o potenciadores de la funcionalidad turística en un determinado momento y contexto geográfico) y/o negativo (limitando o incluso imposibilitando su desarrollo). Tales factores son numerosos y se hallan estrechamente interrelacionados entre sí, siendo individualizables solo a efectos clasificatorios. Atendiendo a su naturaleza son estructurales o de tipo dinámico o coyuntural. Entre estos últimos hay que señalar cuatro fundamentales: 
a) Factores técnicos, como los medios e infraestructuras de comunicación y las estructuras receptivas, que aportan una importante ventaja competitiva.

b) Factores económicos, concretados en la disponibilidad o no de recursos financieros, las directrices monetarias, las crisis cíclicas, etc.

c) Factores institucionales (política turística, promoción, etc.) o geopolíticos (seguridad, estabilidad social del destino...) a los que la demanda es tan sensible.

d) Factores personales, ligados a los valores y percepciones de los consumidores, pero también a las modas, muy influidas hoy por blogueros e influencers.

En cuanto a los estructurales, de carácter más claramente territorial, están directamente ligados a un entorno concreto y por ello gozan de mayor permanencia (pese a la cierta variabilidad también inherente a cualquier área de la superficie terrestre). Cabría clasificarlos en dos grandes grupos:

a) Factores posicionales: relativos a la localización entendida en términos de situación de un determinado destino respecto de los potenciales centros emisores de visitantes, así como respecto de otros posibles espacios turísticos con los que pudiese gozar de una relación de complementariedad. La posición define, pues, la mayor o menor proximidad y accesibilidad tanto física, como en tiempo, coste e, incluso, conocimiento de un determinado territorio turístico.

b) Factores ambientales: concernientes a las condiciones del medio y directamente influyentes sobre las posibilidades de funcionalización turística, son tanto naturales - clima, relieve, agua, elementos bióticos - como culturales - reflejo del proceso de humanización, histórico y actual, de un determinado territorio- - y actúan según su especificidad y las manifestaciones concretas que asuman en cada lugar. Una idea central en la que se debe incidir radica en la relación factores ambientalesrecursos. En este sentido, tal como algunos autores (Gómez, 1999; Vera, Coord., 2014) han remarcado, los recursos territoriales turísticos no son sino componentes ambientales dotados de un interés singular (intrínseco, patrimonial) y de una valoración social que los contempla como atractivos. Dicho de otro modo, los factores ambientales constituyen la base de los de atracción turística.

El trabajo práctico con el alumnado respecto de los factores de localización se centra, siguiendo la misma orientación planteada en temas anteriores, en analizar la incidencia de los diferentes tipos de factores en los ámbitos territoriales de referencia, recurriendo para ello al manejo de las claves explicativas para cada tipo de factor que se exponen en el aula.

Una vez considerados todos los factores que influyen en la dinámica turística y siguiendo la línea argumental trazada en el diseño del curso, el tema 4 está concebido con una orientación eminentemente instrumental y metodológica. En él se aborda la catalogación de los recursos de un territorio dado, tarea imprescindible para conocerlos y poder evaluar su potencial y optar por las alternativas de desarrollo más adecuadas (Leno 1993), lo que debe ser el primer paso para cualquier iniciativa más amplia de ordenación y planificación turística (Leno, 1991). 
Es, no obstante, esta una cuestión compleja debido a la extraordinaria variedad tipológica de los recursos, a la escasa aplicación práctica que ha tenido hasta la fecha y a la diversidad metodológica reflejada en la profusa bibliografía existente. Con todo, la mayor parte de las aportaciones parecen coincidir en que el proceso de catalogación puede articularse a partir de una serie etapas, a saber: manejo de fuentes directas e indirectas (para la identificación y localización de los recursos); inventario (para su descripción y valoración individualizada en fichas de inventariado); evaluación analítica (para la determinación de un índice numérico de valor turístico que muestre el potencial de funcionalización de cada uno y establezca una jerarquía entre ellos); contextualización territorial (donde se reflejen las posibles relaciones funcionales entre los recursos previamente inventariados) (Leno, 1993; López, 1998; Barrado y Ávila, 2010; Vera, Coord., 2014, MINCETUR, 2018). Sin embargo, como se ha apuntado, la falta de coincidencia de las propuestas realizadas es patente (lo que, sin duda, dificulta la praxis de la catalogación), principalmente en los modelos de fichas de inventario y en la definición de índices de potencialidad.

En el primer caso, de los numerosos modelos existentes se muestran algunos al alumnado, reflexionando sobre los distintos criterios utilizados para el análisis y clasificación de los recursos: desde los basados en su naturaleza o formalización (Defert, 1976, 1982; OEA, 1978), a los que ponen el acento en aspectos relativos a su funcionalidad turística (Clawson y Knetsh, 1966; Pellegrini, 1973; Burkart y Medlik, 1986; Leno, 1989). No obstante, más recientemente se está optando por la combinación de ambos tipos de criterios (López, 1998; Barrado y Ávila, 2010; Navarro, 2015), opción por la que nos decantamos, ofreciendo una ficha de inventario propia estructurada en cuatro bloques temáticos secuenciados y donde se recurre a los criterios de clasificación expuestos en el tema 2 (Figura 6).

La información recogida en el inventario es el punto de partida para abordar la evaluación analítica de los recursos (definición del índice de potencialidad turística). También en este caso son múltiples las propuestas existentes (López, 1998; Cebrián y García, 2010; entre otras), siendo quizá el referente principal la clásica de la OEA (1979), sobre la que se han realizado diversas mejoras y adaptaciones (Álvarez y Leno, 1986; MINCETUR, 2006; MINCETUR, 2018); ésta última, centrada en el caso de Perú, es mostrada como ejemplo real y de carácter práctico al alumnado, incluyendo tanto el modelo de ficha de inventario y la aplicación del índice de potencialidad (MINCETUR, 2018), pero también el SIG elaborado para la localización, descripción y valoración de cada uno de los recursos turísticos del país (http://sigmincetur.mincetur.gob.pe/turismo/). Sea como fuere, como ya apuntaba Leno (1991) y como igualmente se remarca a los estudiantes, el punto débil de todas las propuestas existentes no deja de ser la fijación de los coeficientes de ponderación de las distintas variables, único medio de superar la subjetividad connatural a los procesos de evaluación de los recursos turísticos.

La meta de conseguir la mayor objetividad posible tiene por finalidad última, no tanto la valoración individualizada de los recursos sino, fundamentalmente, la delimitación precisa del potencial turístico de las zonas donde estos se encuentran, medio para poder llegar a establecer unidades espaciales (Unidades Ambientales Turísticas en la terminología de López, 1998; Áreas Producto en la más reciente de Barrado y Ávila, 2010) en las que la agrupación de los que están próximos y/o presentan homogeneidad temática y viabilidad para su funcionalización turística permita generar nuevos dinamismos, nuevos nodos turísticos. 


\section{Figura 6 \\ PROPUESTA DE GUÍA BÁSICA PARA LA REALIZACIÓN DEL INVENTARIO DE UN RECURSO TERRITORIAL TURÍSTICO}

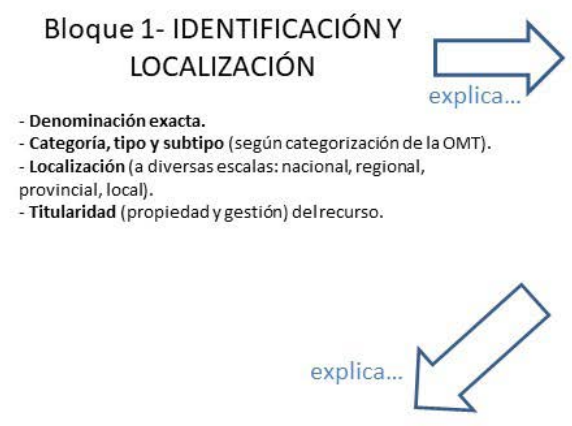

\section{Bloque 2- DESCRIPCIÓN \\ (del recurso territorial y su funcionalidad)}

Caracterización-ordenaday sintética- de su proceso de conformación y sus principales características territoriales y valores.

- Clasificación territorial del recurso: natural, antrópico o antropizado/mixto.

- Especificidad $\rightarrow$ remarcar posibles elementos distintivos y/o singulares del recurso, explicativos de su capacidad de atracción y de la (posible) funcionalidad turística que pueda acoger.

- Estado de conservación actual (del recurso y su entorno más próximo); posibles problemas o situaciones de conflictividad detectados. - Posibles reconocimientos administrativos (legales) y/o instrumentos de ordenación/planificación/protección con incidencia en el recurso - Funcionalidad del recurso $\rightarrow$ funciones/usos - productivos o no- propios del mismo en tanto que elemento territorial, al margen de la posible función turística que pueda acoger.

\footnotetext{
Bloque 3- VALORACIÓN (de su funcionalidad turística)

- Funcionalidad turística $\rightarrow$ relevancia/papel asumido por ella (principal,

secundario, incidental, inexistente).

- Posibles conflictos de uso (con otros usos/funciones del espacio).

- Dotación para el uso turístico:

a) Accesibilidad y señalización (in situ y en su entorno).

b) Infraestructura y/o servicios (generales y turisticos) vinculados al recurso. - Afluencia $\rightarrow$ Cuantificación/estimación del número de visitantes (si existiese), y tipología de los mismos (procedencia fundamental; motivaciones y expectativas). - Inserción (o no) del recurso en el marco de un Espacio-Destino; ¿Consecuencias derivadas de dicha inserción o, por el contrario, de la ausencia de la misma? - Clasificación del recurso según su capacidad de atracción turística (en el contexto territorialen que se sitúa) (según propuesta de la OEA) $\rightarrow$ Recurso básico (una jerarquía de 1 a 5), o complementario.
}

\section{Bloque 4- POTENCIALIDAD} TURÍSTICA

Fuente: Elaboración propia a partir de González y otros, 2015; Leno 1991; 1993; López, 1998; MINCETUR 2006; 2018; Vera, Coord., 2014.

Resultado de lo anterior, la conformación de productos que logren desarrollar y satisfacer una experiencia turística es lo que se aborda en el tema 5 del curso, planteado a modo de culminación del mismo por cuanto en él se analizan las realidades territoriales claves resultantes del uso turístico de los recursos: productos, oferta, destino y región turística.

En el caso del producto turístico, se explica la complejidad del concepto, reflejada en la abundante bibliografía que lo aborda (Ivars, 2004; Vera, Coord., 1997 y 2011; Antón y otros, 2008; OMT, 1998 y 2013; Barrado, 2011; Díaz, 2011; entre otros), si bien todas las aportaciones, aunque con ciertos matices, inciden en algunas ideas nucleares. Se caracteriza como un conjunto interrelacionado de bienes y servicios que, sobre la base de los recursos - en tanto que factor explicativo de cualquier producto-, comprende todo un elenco de facilidades o prestaciones (en forma de infraestructuras, equipamientos y servicios), que hacen posible la práctica turística bajo muy diversas formas, lo que, a su vez, determina la variedad tipológica de los productos. Estos permiten, por una parte, disfrutar de los atractivos que motivaron el viaje - acondicionándolos mediante instalaciones espe- 
cíficas y ofreciendo servicios que faciliten y enriquezcan la visita - ; también cubrir las necesidades básicas de los turistas - proporcionando los medios para el desplazamiento, el alojamiento o la manutención -; y, por último, responder adecuadamente a cualquier otra expectativa de ocio y recreación. Todo lo cual se pone a disposición del usuario tras un proceso de promoción, a través de canales de distribución y comercialización que hacen que pueda "comprar su derecho al uso"5 (Arnandis y Cañas, 2015, 113) con el objeto de dar respuesta a sus motivaciones y obtener una experiencia turística satisfactoria.

\section{Figura 7 \\ CONCEPTUALIZACIÓN DIDÁCTICA E IDEAL DE LOS COMPONENTES DE UN PRODUCTO TURÍSTICO}

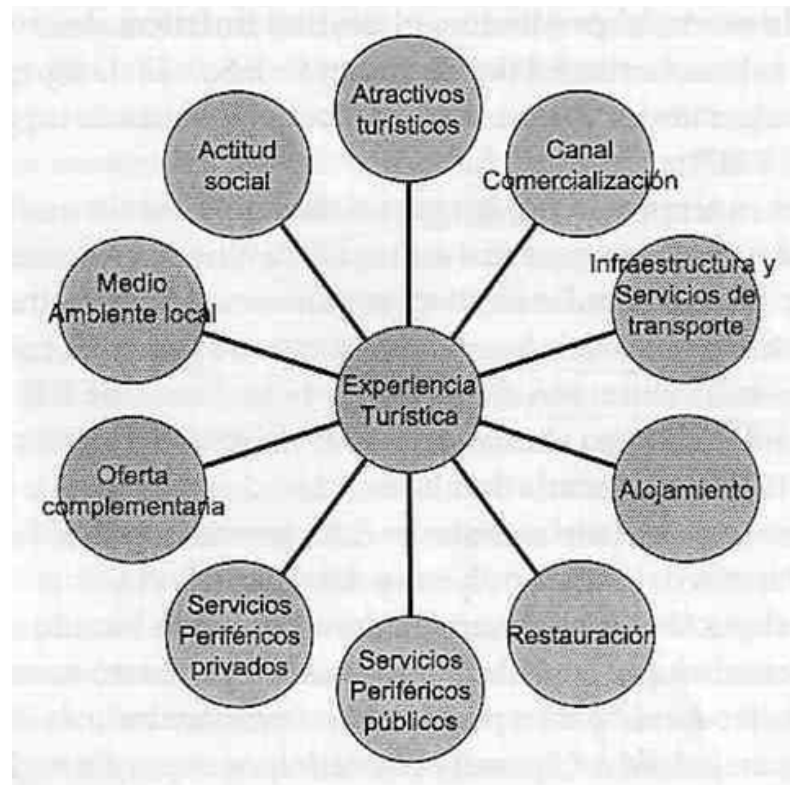

Fuente: Ivars, 2004

En consonancia con lo anterior, durante la práctica docente se ejemplifican los tipos de productos turísticos existentes (disfrute e interpretación de recursos, información, alojamiento, manutención y ocio y comercio, principalmente), remarcándose asimismo que no solo tienen utilidades estrictamente funcionales, sino que también permiten experimentar vivencias y sentir emociones vinculadas a ellas. Además, integran componentes de naturaleza simbólica, social o incluso ambiental que son objeto de valoración y llegan a condicionar en buena medida la percepción del visitante. Se trata, pues, de una realidad

5 Aunque no debe olvidarse que, como señala Barrado (2011), estos coexisten con bienes libres, sin precio de mercado y, por lo tanto, no comercializables (con frecuencia, de carácter geográfico como el paisaje, la playa o el patrimonio urbanístico) que, en ocasiones, incluso llegan a convertirse en el mayor atractivo y en el fundamento del producto turístico conformado. 
compleja que se expresa de forma integrada y que es capaz de provocar sensaciones, no tanto por la particularidad de cada uno de los elementos que el turista utiliza (ya sean recursos, infraestructuras, equipamientos o servicios) sino por las interrelaciones desplegadas entre todos ellos dentro de lo que el visitante vive como una experiencia unitaria (Figura 7).

Para consolidar la conceptualización de los productos turísticos, una sesión práctica muy útil e interesante, que se desarrolla con el alumnado en el aula, radica en ofrecerles un listado con realidades territoriales que constituyen bien recursos turísticos bien productos turísticos, con el objetivo de que puedan diferenciarlos con claridad.

Más allá de la conceptualización básica del producto turístico, un paso posterior y que consideramos imprescindible estriba en remarcar la visión de conjunto y la coordinación entre todos los integrantes del producto, de forma que sea posible crear o reforzar las sinergias que propicien la competitividad y el éxito (Vera, Coord., 2014). Se trata, en otras palabras, de lograr una adecuada ordenación de la oferta, en el marco de un destino dado.

A este respecto, en el curso se destaca muy especialmente la tendencia a la polarización de la actividad, a raíz de la concentración de los productos en nodos de funcionalización turística (Figura 8). En este sentido, la imagen que el turista recibe y reconoce, la imagen proyectada del destino y su oferta, corresponde a la de un lugar identificable por su función que, evidentemente, está asentada sobre una base territorial determinada, pero que no en todos los casos resulta coincidente con una realidad física o administrativa. Ello no es óbice, sin embargo, para remarcar su carácter territorial, lo cual determina que en él confluyan todos los componentes de cualquier espacio geográfico, en interacción con los propios del sistema turístico, definiendo en su conjunto un verdadero sistema territorial turístico (Vera. Coord., 2014; Simancas, Coord., 2016).

\section{Figura 8 \\ ESQUEMA CONCEPTUAL DE UN DESTINO TURÍSTICO}

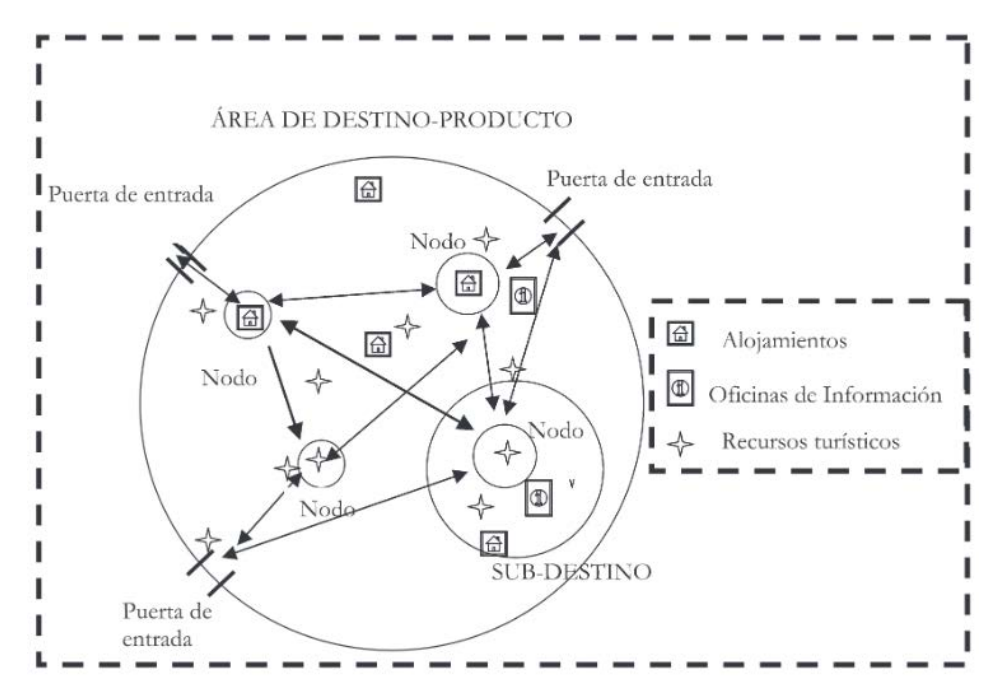

Fuente: Ávila y Barrado, 2005. 
La complejidad de dicho sistema, expresada de manera visual en la Figura 9 donde se aplica la metodología de aproximación sistémica al territorio (Montiel y otros, 2013), permite definir una serie de subsistemas, que en el caso del destino pueden concretarse en:

- Subsistema físico-ambiental: incluye los factores posicionales y ambientales de localización turística; a partir de estos últimos se destacan los de atracción o recursos turísticos.

- Subsistema socioeconómico: conlleva el análisis de la población y el poblamiento, así como de la estructura económica del territorio.

- Subsistema específicamente turístico: comprende el estudio de las dotaciones (infraestructuras, equipamientos y servicios) que determinan la conformación de productos, la demanda, y los impactos derivados de la funcionalización turística.

- Subsistema de ordenación y gestión: plantea los instrumentos de ordenación del territorio turístico, las disposiciones incluidas en ellos y las iniciativas de gestión derivadas y aplicadas. Los fundamentos para el adecuado tratamiento de este subsistema, en razón de su propia naturaleza, deben abordarse en una asignatura ulterior de Planificación y Ordenación del Territorio Turístico.

Figura 9

\section{COMPONENTES CLAVE DEL DESTINO DESDE UNA VISIÓN SISTÉMICA}

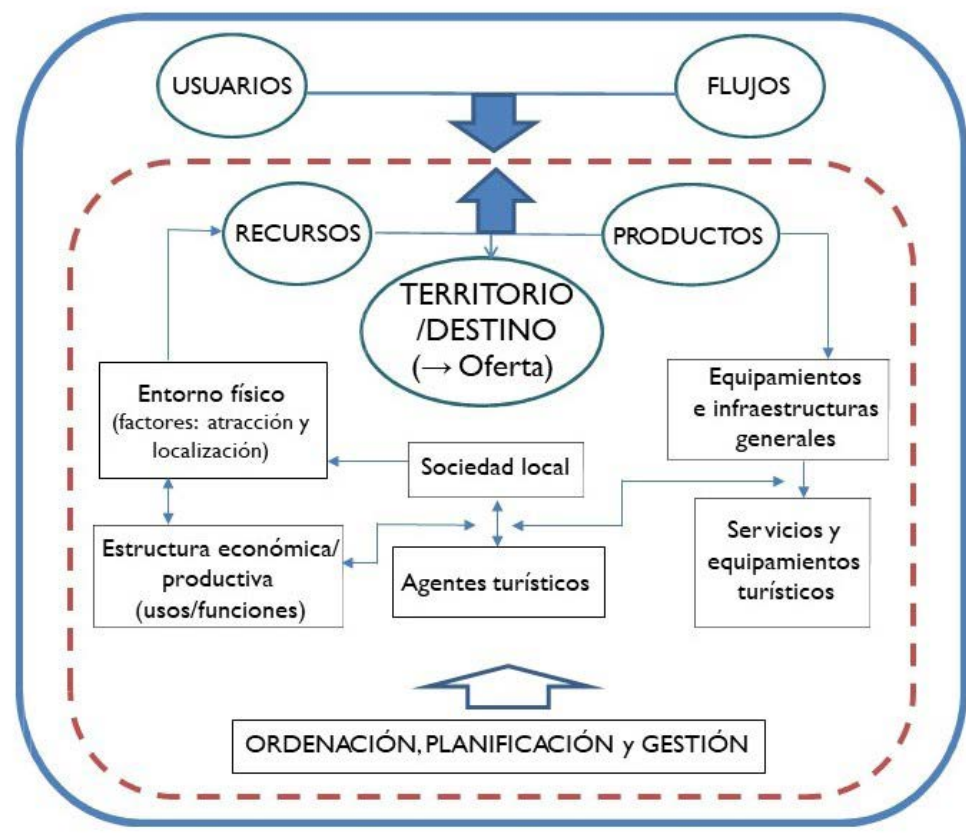

Fuente: Elaboración propia a partir de Almirón, 2004; Ávila y Barrado, 2005; Barrado, 2004; Pearce, 2014; Simancas, Coord., 2016; Vera, Coord., 2014. 
La metodología de análisis sistémico de destinos se aplica en el curso, mediante sesiones prácticas desarrolladas en el aula, a ejemplos seleccionados por su representatividad, al reflejar dinámicas de especial interés tales como un factor posicional muy favorable y el uso público como base de la función turística en un espacio protegido de alto valor (Figura 10), o la variedad de recursos y de experiencias posibles en una gran ciudad (Figura 11).

Pero, además, como trabajo de carácter práctico para el alumnado, el examen de un territorio turístico (aquel que se hubiese venido analizando en los grupos de trabajo de 2-3 estudiantes ya conformados desde el comienzo de la asignatura) según este enfoque metodológico sistémico es la principal tarea propuesta en el marco de la asignatura de Recursos Territoriales Turísticos, por su carácter integrador de los grandes contenidos de la asignatura y por la posibilidad de manejar fuentes (sobre todo, oficiales) muy diversas.

Respecto de la variedad tipológica de territorios turísticos, la asignatura no la aborda e specíficamente por considerar más idóneo analizarla en profundidad en la de Planificación y Ordenación del Territorio Turístico.

El tema 5 culmina con la consideración de la región turística como conjunto de destinos con vinculación funcional, cuyas sinergias la configuran como un ámbito dinámico y reconocible (Figura 12). Desde una perspectiva tipológica, la praxis turística permite identificar dos tipos básicos de regiones: por una parte, las conformadas por destinos muy similares en su capacidad de atracción, lo que genera una competencia directa entre ellos, pudiendo llegar a definir auténticas redes; por otra, las articuladas a partir de un destino principal con gran capacidad de atracción y que se constituye como referente para importantes flujos de usuarios, pero que cuenta con otros próximos con menor jerarquía que actúan (o pueden hacerlo) como complemento de aquél, pudiendo calificarse como traspaís turístico del primero (Suchet, 2017).

Estas modalidades de integración se pueden manifestar a diversas escalas: supranacional (regiones turísticas del Mediterráneo, El Caribe, Escandinavia, etc.); regional (vinculación entre grandes núcleos urbano-culturales en Castilla y León, Andalucía, u otras; o entre grandes espacios naturales próximos entre sí - por ejemplo, dentro de importantes sistemas montañosos de alta funcionalidad turística como los Alpes, Pirineos o la Cordillera Cantábrica - ...) (Figura 13); e incluso subregional, en el caso, sobre todo, de grandes destinos litorales o urbanos con traspaíses turísticos complementarios próximos a ellos (Costa del Sol-interior de la provincia de Málaga, o Madrid-ámbitos patrimoniales próximos - como El Escorial o Aranjuez, entre otros - , son algunos de los ejemplos expuestos en el aula). En cualquiera de las situaciones, la mayor virtualidad de la región turística radica en su sentido operativo, el cual apunta a una deseable planificación y promoción conjunta de destinos que evidencian una clara vinculación funcional entre sí, algo que, tal y como se ha remarcado (Simancas, Coord., 2016), tan solo comienza a hacerse patente de manera muy incipiente en el contexto actual. 


\section{Figura 10 \\ OFERTA DE RUTAS GUIADAS EN EL PARQUE NACIONAL PICOS DE EUROPA, EJEMPLO DE OFERTA DE ECOTURISMO}

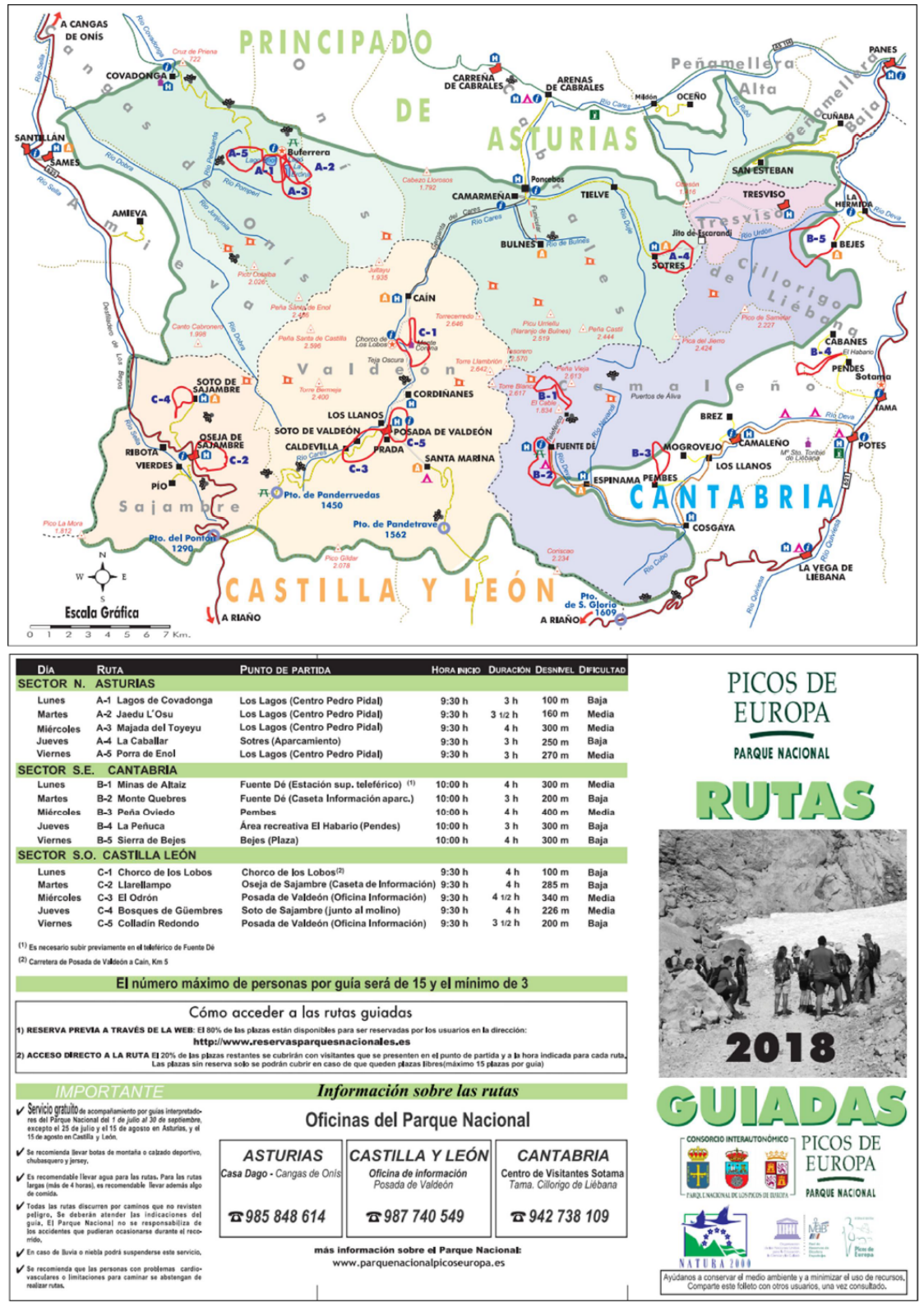

Fuente: https://www.miteco.gob.es/es/red-parques-nacionales/nuestros-parques/picos-europa/rutas-guiadas-2019 tcm30-422429.pdf[consulta: 6-11-2019] 
Figura 11

BARCELONA, EJEMPLO DE MULTIFUNCIONALIDAD TURÍSTICA SOBRE LA BASE DE LA DIVERSIDAD DE SUS RECURSOS TERRITORIALES

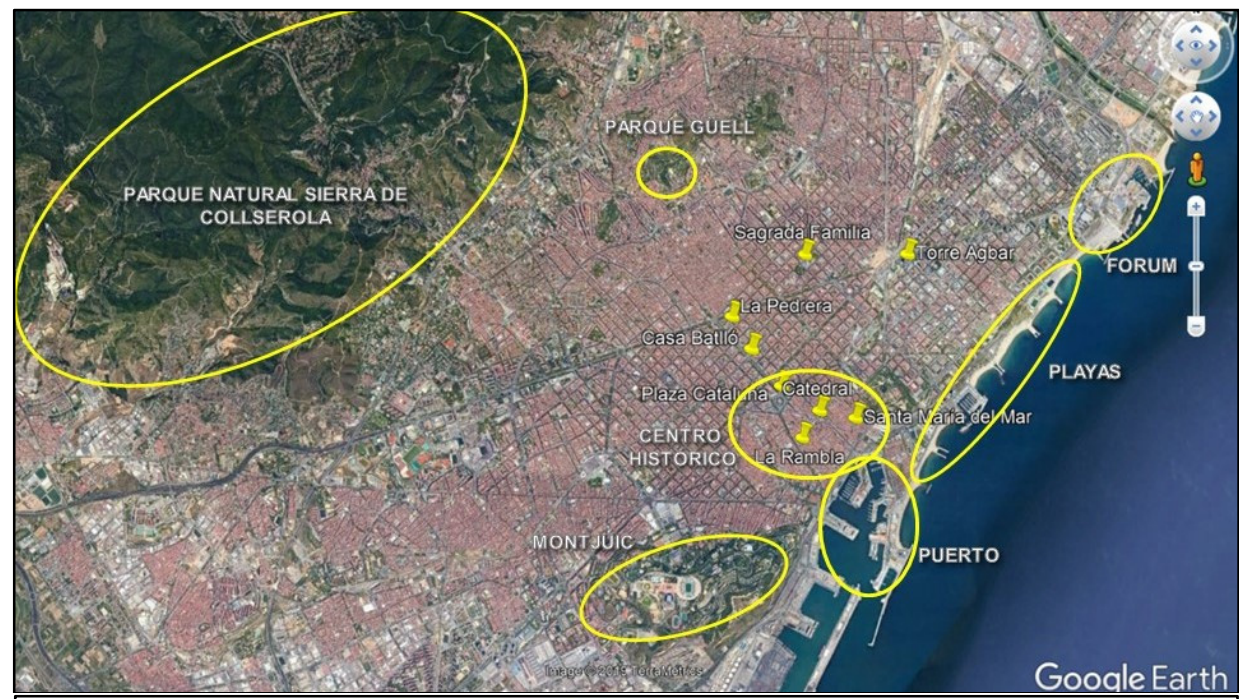

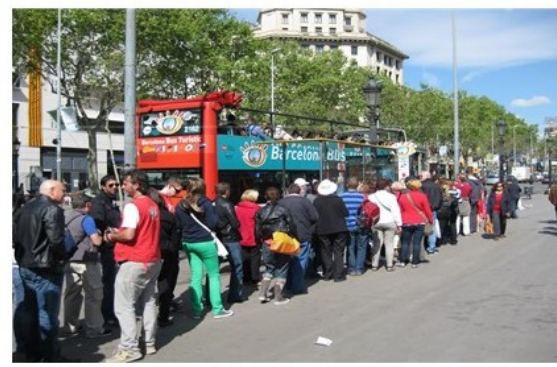

Turismo urbano

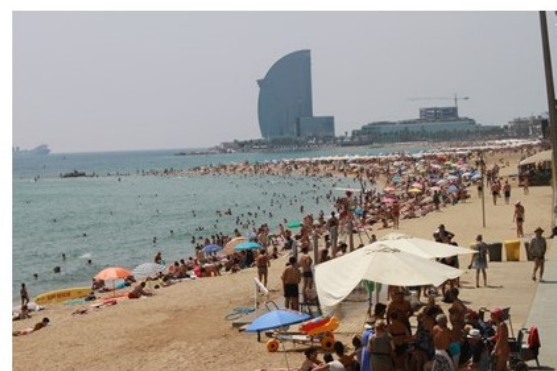

Turismo de sol y playa

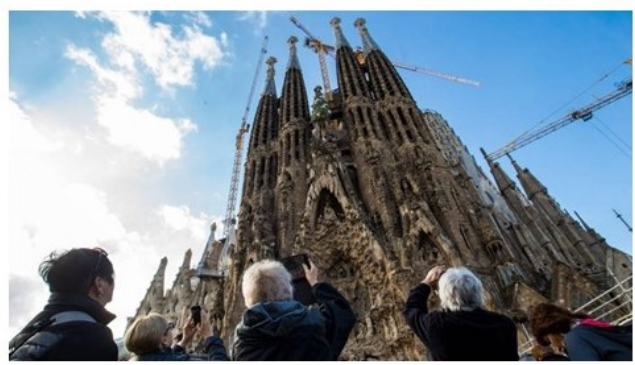

Turismo monumental

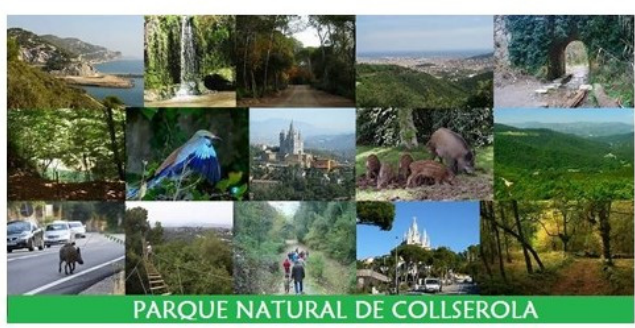

Turismo de naturaleza

Fuente: Google Earth, www.parcnaturalcollserola.cat. Elaboración propia. 


\section{Figura 12 \\ MODELO TEÓRICO DE UNA REGIÓN TURÍSTICA COMO CONJUNTO DE DESTINOS FUNCIONALMENTE RELACIONADOS}

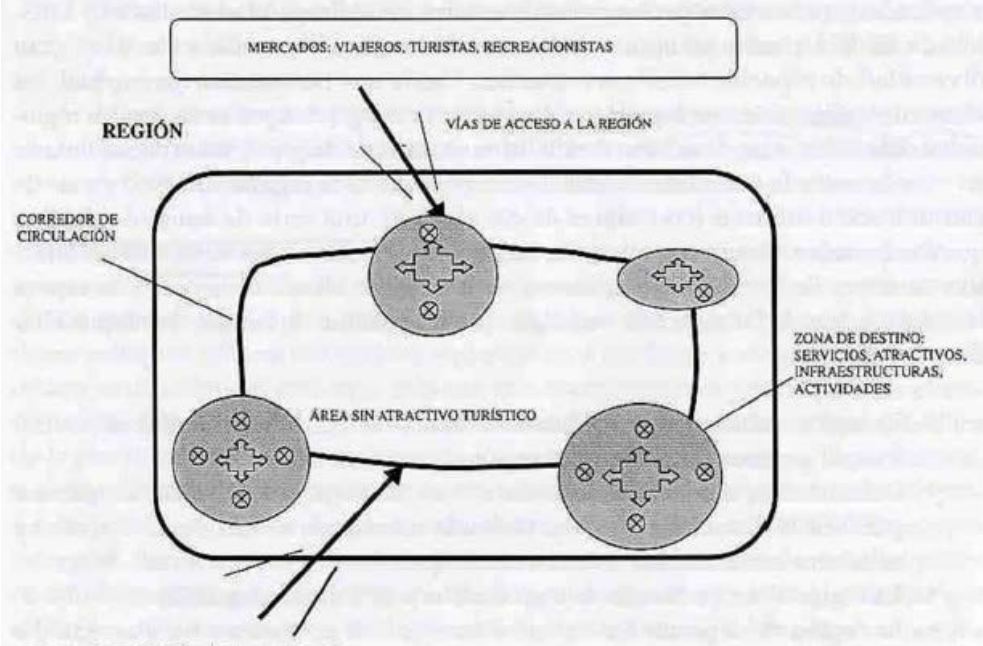

Fuente: Ivars (2004), a partir de Gunn (1994).

Figura 13

REGIÓN TURÍSTICA PROPUESTA POR EL PLAN DE ORDENACIÓN DEL TERRITORIO DE ANDALUCÍA A PARTIR DE LA INTERRELACIÓN ENTRE LOS TRES PRINCIPALES DESTINOS URBANO-PATRIMONIALES DE INTERIOR

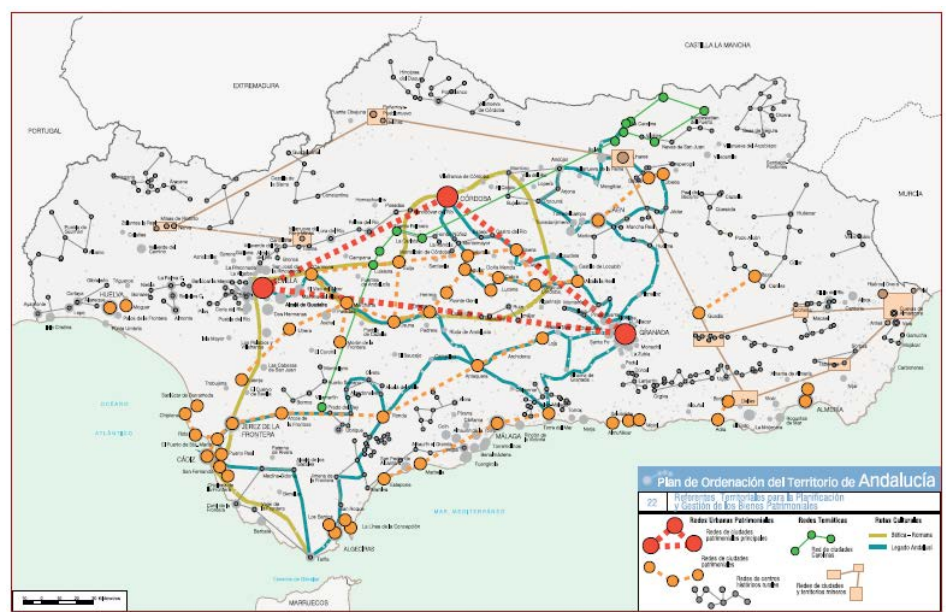

Fuente: Material docente de la asignatura, tomado del Plan de Ordenación del Territorio de Andalucía (2006). 


\section{CONCLUSIONES}

Aunque solo reconocida desde fechas relativamente recientes, la estrecha e indisoluble interrelación existente entre turismo y territorio explica el interés, más aún, la evidente necesidad del análisis geográfico de la práctica turística y la inserción de la dimensión territorial en el actual Grado universitario en la materia.

A este respecto, el Libro Blanco del Título del Grado de Turismo elaborado por la ANECA para guiar el diseño de los estudios adaptado al EEES otorga un significativo peso a este tipo de contenidos. Sin embargo, por la propia configuración del documento, concebido a modo de guía orientativa a partir de la que cada universidad debería configurar su particular plan de estudios, el resultado ha sido una acusada disparidad en las materias tratadas, tanto por la heterogeneidad en las asignaturas implementadas como por la distinta composición temática y cuestiones a abordar. En estas circunstancias, la conveniencia de alcanzar un cierto consenso, al menos, en lo que constituyen las claves conceptuales y metodológicas que debieran fundamentar el análisis territorial del turismo, parece evidente.

Con este objetivo, aquí hemos hecho una propuesta de estructuración para la asignatura de Recursos Territoriales Turísticos (temática esencial entre las competencias para el desarrollo del título), la cual se ocupa del conocimiento de los componentes de un espacio que es imprescindible para la actividad y que constituye, a nuestro juicio, la base sobre la que apoyar el posterior estudio de las dinámicas turísticas y la práctica de la ordenación y gestión de los destinos.

Como decimos, situándose en el marco de lo recogido en el Libro Blanco del Grado de Turismo, se trata de un planteamiento didáctico y propositivo, por lo cual está abierto a la discusión y la posible modificación, más aún si se consideran las rápidas y profundas transformaciones que el sector está viviendo en los últimos años, así como sus efectos sobre los distintos elementos del sistema turístico. No obstante, con el respaldo que le otorga la práctica docente de los autores, creemos que se trata de una apuesta coherente y bien fundamentada, que puede contribuir a la clarificación y mejor articulación del estudio territorial turístico y a un desarrollo epistemológico y metodológico de utilidad para el mismo.

Conviene considerar, no obstante, que solo hemos pretendido realizar una aproximación al tema y no una exposición detallada, algo que excedería por mucho las posibilidades de una publicación como esta. Aun así, se han revisado los concepto se ideas que constituyen el armazón de la asignatura, se han señalado, ordenado y sintetizado los principales contenidos de cada uno de los temas, se han expuesto los aspectos procedimentales y metodológicos que parecen más significativos para la docencia y se han aportado materiales e instrumentos de utilidad tanto para una mejor comprensión de los contenidos por parte del alumnado como para una aplicabilidad práctica de los mismos, cuya finalidad última es conseguir una adecuada ordenación y gestión del espacio turístico (cuestión esta abordada por extenso en asignaturas posteriores).

El resultado es un modelo para la organización de la asignatura que entendemos que puede ser de utilidad para los interesados en la materia, que pretende mover a la reflexión y servir de referencia a la hora de afrontar una posible reestructuración de la enseñanza universitaria relativa a la vertiente territorial del fenómeno turístico. 


\section{BIBLIOGRAFÍA}

ALMIRÓN, A.V. (2004): "Turismo y espacio. Aportes para otra geografía del turismo". GEOUPS. Espaço e Tempo, n 16, pp. 166-180.

ÁLVAREZ CUERVO, R. y LENO CERRO, F. (1986): Estudio para la valoración económica y situación estructural del mercado turístico riojano. Instituto de Estudios Turísticos, Gobierno de La Rioja, vol. 3.

ANECA (2004): Libro Blanco del Título de Grado en Turismo. Madrid, Agencia Nacional de Evaluación de la Calidad y Acreditación.

URL: http://www.aneca.es/var/media/359791/libroblanco_turismo_03.pdf

ANTÓN CLAVÉ, S.; FERNÁNDEZ TABALES, A. y GONZÁLEZ REVERTÉ, F. (2007): "Los lugares turísticos”. En ANTÓN CLAVÉ, S., GONZÁLEZ REVERTÉ, F. (Coords.): A propósito del turismo: la construcción social del espacio turístico. Barcelona, OUC, pp. 103-206.

ANTÓN ClAVÉ, S.; BLAY BOQUÉ, J. y SALVAT SALVAT, J. (2008): “Turismo, actividades recreativas y uso público en los parques naturales. Propuesta para la conservación de los valores ambientales y el desarrollo productivo local". Boletín de la Asociación de Geógrafos Españoles, no 48, pp. 5-38.

ARNANDISIAGRAMUNT, R. (2019): “QQué es un recurso turístico? Un análisis DELPHI a la academia hispana". Cuadernos de Turismo, $\mathrm{n}^{\circ}$ 43, pp. 39-68.

ARNANDIS I AGRAMUNT, R. y CAÑAS MARTÍ, L. (2015): "Recurso cultural, recurso turístico, producto turístico ¿qué creó realmente el plan piloto de dinamización del producto turístico de Xátiva (Valencia)? En LÓPEZ, D. (Ed.): Del territorio al destino turístico: retos y claves de éxito. XVII Congreso Internacional de Turismo Universidad Empresa. Valencia, Tirant lo Blanch, pp. 107-129.

ÁVILA BERCIAL, R. y BARRADO TIMÓN, D. (2005): "Nuevas tendencias en el desarrollo de destinos turísticos: Marcos conceptuales y operativos para su planificación y gestión", Cuadernos de Turismo, n 15, pp. 27-43.

BARRADO TIMÓN, D.A. (2004): "El concepto de destino turístico. Una aproximación geográfico-territorial", Estudios Turísticos, n 160, pp. 45-68.

BARRADO TIMÓN, D.A. (2011): "Recursos territoriales y procesos geográficos: el ejemplo de los recursos turísticos", Estudios Geográficos, n 270, pp. 35-58.

BARRADO TIMÓN, D. y ÁVILA BERCIAL, L. (2010): "El tratamiento del espacio y de la actividad turística desde la perspectiva territorial". En GALIANA, L. y VINUESA, J. (Coords.): Teoría y práctica para una ordenación racional del territorio. Madrid, Síntesis, pp. 153-179.

BECERRA, J.M. (2005): "Los recursos patrimoniales y el desarrollo territorial". En CARAVACA, I. y FERNÁNDEZ SALINAS, V. (Coords.): Jornadas de Patrimonio y Territorio. Sevilla, Junta de Andalucía, pp. 71-81.

BUTLER, R. W. (1980): "The concept of a tourist area cycle of evolution: implications for management of resources", Canadian Geographer, vol. 24 (1), pp. 5-12.

BUTLER, J.H. (1986): Geografía económica. Aspectos espaciales y ecológicos de la actividad económica. México, Limusa. 
CAÑIZARES RUIZ, M.C. (2009): “Cultura y patrimonio en clave territorial: las aportaciones del geógrafo”. En FERIA, J.M. y otros (Eds.): Territorios, Sociedad y Políticas. Sevilla, Universidad Pablo de Olavide. AGE, pp. 93-106.

CASTILLO RUIZ, J. (2009): “La dimensión territorial del patrimonio histórico". En CASTILLO RUIZ, J., CEJUDO GARCÍA, E. y ORTEGA RUIZ, A. (Coords.): Patrimonio histórico y desarrollo territorial. Sevilla, Universidad Internacional de Andalucía, pp. 26-48.

CEBRIÁN ABELLÁN, F. y GARCÍA GONZÁLEZ, J.A. (2010): “Propuesta metodológica para la investigación, clasificación y puesta en valor de los recursos territoriales del turismo interior. La provincia de Albacete", Boletín de la Asociación de Geógrafos Españoles, $n^{\circ}$ 54, pp. 361-383.

CONSEJO DE EUROPA (2000): Convenio Europeo del Paisaje. Florencia, Consejo de Europa.

URL:https://www.mapa.gob.es/es/desarrollo-rural/planes-y-estrategias/desarrollo-territo$\mathrm{rial} / \mathrm{convenio.aspx}$

COOPER, C. y otros (2007): El turismo: teoría y práctica. Madrid, Síntesis.

DÍAZ, B. (2011): Diseño de productos turísticos. Madrid, Síntesis.

DORTA-AFONSO, D. (2018): "Docencia universitaria en Turismo: la metodología de casos aplicada a las áreas de organización de empresas, marketing, comercialización e investigación de mercados". Revista Atlante.

URL: https://www.eumed.net/rev/atlante/2018/11/docencia-universitaria-turismo.html

EJARQUE BERNET, J. (2005): Destinos turísticos de éxito. Diseño, creación, gestión y marketing. Madrid, Pirámide.

FLORIDO TRUJILLO, G. (2013): "El Patrimonio Territorial en el Plan de Ordenación del Territorio de Andalucía: indefiniciones y dificultades para un conocimiento preciso", Boletín de la Asociación de Geógrafos Españoles, no 63, pp. 163-201.

GALIANA, L. y VINUESA, J. (2010): Teoría y práctica para una gestión racional del territorio. Madrid, Síntesis.

GARCÍA MANJÓN, J.V. y PÉREZ LÓPEZ, M.C. (2008): "El Grado de Turismo: un análisis de las competencias profesionales", Cuadernos de Turismo, no 21, pp. 67-83.

GÓMEZ MARTÍN, B. (1999): "La relación clima-turismo: consideraciones básicas en los fundamentos teóricos y prácticos”, Investigaciones Geográficas, n 21, pp. 21-34.

GONZÁLEZ DE SOUSA, M.A., JIMÉNEZ GONZÁLEZ, A. y MARTÍN VALLÉS, D. (2015): El inventariado de los recursos turísticos: un enfoque desde la demanda. Madrid, Ministerio de Industria, Energía y Turismo. EOI Escuela de Organización Industrial.

GUNN, C. (1994): Tourism planning: basic, concepts and cases. Washington, Francis and Taylor.

HIERNAUX-NICOLAS, D. (1994): "En busca del Edén: turismo y territorio en las sociedades modernas", Ciudades, Revista de la Red Nacional de Investigación Urbana, $\mathrm{n}^{\circ}$ 23, pp. 24-31.

IVARS BAIDAL, J.A. (2004): Planificación turística de los espacios regionales en España. Madrid, Síntesis. 
JIMÉNEZ HERRERO, L.M. (Dir.) (2009): Patrimonio natural, cultural y paisajístico. Claves para la sostenibilidad territorial. Madrid, OSE. URL: http://www.upv.es/contenidos/CAMUNISO/info/U0556177.pdf

LENO CERRO, F. (1991): "Los recursos turísticos en un proceso de planificación: inventario y evaluación", Papers de Turisme, n 7, pp. 7-23.

LENO CERRO, F. (1993): Técnicas de evaluación del potencial turístico. Madrid, Dirección General de Política Turística, Secretaría General de Turismo.

LOIS GONZÁLEZ, R.C. (2008): "Turismo y territorio a principios del siglo XXI. Una reflexión geográfica desde el ámbito de la gestión pública”. En TROITIÑO, M.A. et al. (Coords.): Destinos turísticos: viejos problemas ¿nuevas soluciones? Actas del X Coloquio de Geografía del Turismo, Ocio y Recreación. Ciudad Real, Universidad de Castilla-La Mancha.

LÓPEZ BONILLA, J.M. y LÓPEZ BONILLA, L.M. (2007): "Diferencias territoriales en la planificación y la gestión del destino turístico", Cuadernos de Turismo, n ${ }^{19}$, pp. 71-90.

LÓPEZ OLIVARES, D. (1998): La ordenación y planificación integrada de los recursos territoriales turísticos. Castellón, Servicio de Publicaciones de la Universidad Jaume I.

LOZATO-GIOTART, J.P. (1990): Geografía del Turismo: del espacio contemplado al espacio consumido. Barcelona, Masson.

MAJÓ FERNÁNDEZ, J. (2005): “Competencias o capacidades profesionales que deben aportar las nuevas titulaciones al Sistema Turístico". En VV.AA.: Armonización de los Estudios de Turismo en el Espacio Europeo de Enseñanza Superior. Valladolid, Universidad Europea Miguel de Cervantes, pp. 61-86.

MAJÓ, J, GALÍ, N. y MINISTRAL, M. (2000): “Educación y formación en el sector turístico". En VV.AA.: Actas del III Congreso Universidad Empresa. Castellón, Tirant lo Blanch, pp. 759-772.

MATA OLMO, R. (2006): "Un concepto de paisaje para la gestión sostenible del territorio”. En MATA OLMO, R. y TARROJA, A.: El paisaje y la gestión del territorio. Criterios paisajísticos en la ordenación del territorio y el urbanismo. Barcelona, Diputació de Barcelona CUIMP, pp. 17-40.

MATA OLMO, R. (2008): "El paisaje, patrimonio y recurso para el desarrollo territorial sostenible. Conocimiento y acción pública", Arbor Ciencia, Pensamiento y Cultura, $\mathrm{n}^{\mathrm{o}} 729$, pp. 155-172.

MINCETUR (2006): Manual para la formulación del Inventario de Recursos Turísticos a Nivel Nacional. Lima, Ministerio de Comercio Exterior y Turismo.

MINCETUR (2018): Manual para la elaboración y actualización del inventario de recursos turísticos. Lima, Ministerio de Comercio Exterior y Turismo.

MONTIEL MOLINA, C. y otros (2013): Guía docente del proyecto de ordenación del territorio: Análisis y diagnóstico de los subsistemas territoriales. Madrid, Universidad Complutense.URL:https://www.ucm.es/data/cont/media/www/pag104055/530-2013-10-17-GuiaDocenteOrdTerr_2013.pdf

NAVARRO, D. (2015): "Recursos turísticos y atractivos turísticos: conceptualización, definición y valoración”, Cuadernos de Turismo, n 35, pp. 335-357. 
ORGANIZACIÓN MUNDIAL DEL TURISMO (2005): Indicadores de desarrollo sostenible para los destinos turísticos. Guía práctica. Madrid OMT. URL: https://www.eunwto.org/doi/book/10.18111/9789284408382

ORGANIZACIÓN MUNDIAL DEL TURISMO (2013): Manual de desarrollo de productos turísticos. Madrid, OMT.URL:https://www.unwto.org/archive/global/publication/ manual-de-desarrollo-de-productos-turisticos

ORTEGA VALCÁRCEL, J. (1998): "El Patrimonio Territorial: el territorio como recurso cultural y económico", Ciudades, n 4, pp. 33-48.

PEARCE, D. (2014): "Destinos turísticos: conceptos e implicaciones para su gestión en tiempos de cambio". En LÓPEZ PALOMEQUE, F. y CÀNOVES VALIENTE, G. (Eds.). Turismo y territorio. Innovación, renovación y desafíos. Valencia, Tirant Humanidades, pp. 21-34

ROCH, F. (1998): "El territorio como recurso", Ciudades, n 4, pp. 73-94.

SILVA PÉREZ, R. (2008): “Agricultura, paisaje y patrimonio territorial: los paisajes de la agricultura vistos como patrimonio”, Boletín de la Asociación de Geógrafos Españoles, $\mathrm{n}^{\circ} 49$, pp. 309-334.

SILVA PÉREZ, R. y FERNÁNDEZ SALINAS, V. (2008): "El patrimonio y el territorio como activos para el desarrollo desde la perspectiva del ocio y el turismo", Investigaciones Geográficas, ${ }^{\circ}$ 46, pp. 69-88.

SIMANCAS CRUZ, M. (Coord.) (2016): La planificación y gestión territorial del turismo. Madrid, Síntesis.

SUCHET, A. (2017): "Le concept d'arrière-pays en géographie: une promenade dans la littérature”, Ería: Revista cuatrimestral de Geografía, vol. 37, n 2, pp. 125-130.

TORRES VALDÉS, R. y otros (2017): “Aprendizaje experiencial: Diseño de un laboratorio de innovación social y turismo sostenible”. En ROIG-VILA, R. (Ed.): Investigación en docencia universitaria. Barcelona, Octaedro, pp. 452-461.

TROITIÑO VINUESA, M.A. y TROITIÑO TORRALBA, L. (2018): "Visión territorial del patrimonio y sostenibilidad del turismo", Boletín de la Asociación de Geógrafos Españoles, $\mathrm{n}^{\mathrm{0}}$ 78, pp. 212-244.

VARGAS ULATE, G. (2012): "Espacio y territorio en el análisis geográfico”, Reflexiones, vol. $91, \mathrm{n}^{\mathrm{o}} 1$, pp. 313-326.

VERA REBOLLO, J.F. (Coord.) (1997): Análisis territorial del Turismo. Barcelona, Ariel.

VERA REBOLLO, J.F. (Coord.) (2014): Análisis territorial del turismo y planificación de destinos turísticos. Valencia, Tirant Humanidades.

VERA REBOLLO, F. y BAÑOS CASTIÑEIRA, C. (2016): "La dimensión territorial del turismo. Los objetos de la ordenación territorial de áreas turísticas: la definición del sistema turístico”. En SIMANCAS CRUZ, M. (Coord.): La planificación y gestión territorial del turismo. Madrid, Síntesis, pp. 51-82.

ZOIDO NARANJO, F. (1998): “Geografía y Ordenación del Territorio”, Íber. Didáctica de las Ciencias Sociales. Geografía e Historia, n 16, pp. 19-31. 